\title{
Sexual objectification, self-objectification, self-efficacy, and female identity development: A preliminary study
}

\author{
Kathleen Reilly Coffers \\ West Virginia University
}

Follow this and additional works at: https://researchrepository.wvu.edu/etd

\section{Recommended Citation}

Coffers, Kathleen Reilly, "Sexual objectification, self-objectification, self-efficacy, and female identity development: A preliminary study" (2006). Graduate Theses, Dissertations, and Problem Reports. 769. https://researchrepository.wvu.edu/etd/769

This Thesis is protected by copyright and/or related rights. It has been brought to you by the The Research Repository @ WVU with permission from the rights-holder(s). You are free to use this Thesis in any way that is permitted by the copyright and related rights legislation that applies to your use. For other uses you must obtain permission from the rights-holder(s) directly, unless additional rights are indicated by a Creative Commons license in the record and/ or on the work itself. This Thesis has been accepted for inclusion in WVU Graduate Theses, Dissertations, and Problem Reports collection by an authorized administrator of The Research Repository @ WVU. For more information, please contact researchrepository@mail.wvu.edu. 


\title{
Sexual Objectification, Self-Objectification, Self-Efficacy, and Female Identity Development: A Preliminary Study
}

\author{
By \\ Kathleen Reilly Coffers
}

\section{A THESIS}

\section{Submitted to}

The College of Human Resources and Education at West Virginia University in partial fulfillment of the requirements for the degree of

\author{
Master of Arts \\ in \\ Educational Psychology \\ Department of Technology, Learning and Culture

\section{Morgantown, West Virginia} \\ 2006 \\ Carol A. Markstrom, Ph.D., Chair \\ Erron L. Huey, Ph.D. \\ John B. Jacob, Ph.D.
}

Keywords: sexual objectification, self-objectification, self-efficacy, female identity development

Copyright 2006 Kathleen Reilly Coffers 


\title{
ABSTRACT \\ Sexual Objectification, Self-Objectification, Self-Efficacy, and Female Identity Development: A Preliminary Study
}

\author{
By
}

\author{
Kathleen Reilly Coffers
}

Sexual and self-objectification, self-efficacy and identity status were investigated using data collected from undergraduate and graduate classes from West Virginia University. Subjects were 267 females, ages $18-23$. The four variables were measured as follows: (a) Cultural Sexual Objectification Questionnaire, (b) Self-Objectification Questionnaire, (c) Self-Efficacy Scale and (d) Extended Version of the Objective Measure of Ego Identity Status. Cronbach's Alphas were performed on all measures with good to adequate reliabilities (.69 through .89), with the exception of the identity diffusion subscale which resulted in marginal reliability (.57).Chi-square analyses performed for sexual and self-objectification in each of the four identity statuses showed that $42-68 \%$ of females felt objectified. Hierarchical and stepwise regression analyses were conducted to measure the relations between the independent variables and identity status in which self-efficacy was entered first with the remaining two independent variables entered in a forward, stepwise manner. Predictive models were found for three identity statuses: moratorium, foreclosure and diffusion. The hypotheses in this study were partially supported and results were consistent with prior research where applicable. 


\section{ACKNOWLEDGEMENTS}

I owe my deepest and sincere thanks to Dr. Carol Markstrom. Your instruction and guidance helped transform me into a researcher and a more eloquent writer. Thanks for literally nudging me on when I did not feel like budging. And, thanks for the laughs. This was quite a lot of fun. Thanks, Dr. Huey, for being such a great mentor and for your insistence that I choose my words wisely, at least in written form. You were often there when I needed to blow off steam. And, the tunes weren't so bad, either. And my deepest

gratitude goes to Dr. Jacob. The sensitivity that you brought to this project has opened my eyes wider than any lit review could. I learn from you with every interaction I have with you. Thank you.

I must also give thanks to my friends and family who supported me during the last two years. The constant reminders that I could complete this thesis gave me faith when I had none. Laurie, you are the best. And, Sean and Ross, you paid the ultimate price. The family time that this project has infringed upon could never be returned. Thanks for letting me do what I needed to do. 


\section{TABLE OF CONTENTS}

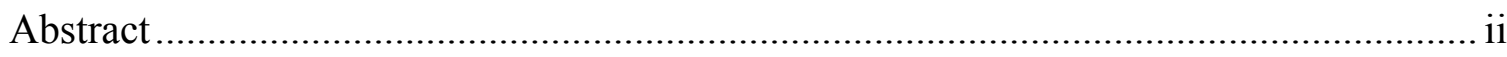

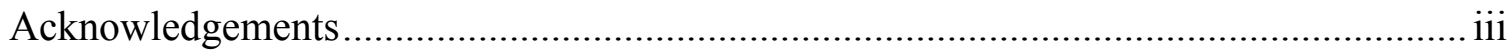

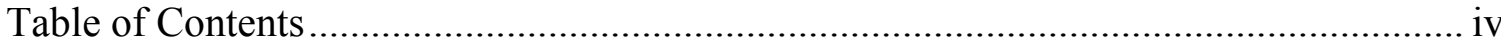

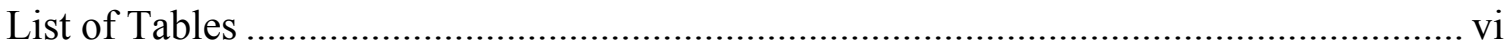

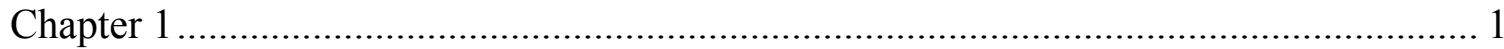

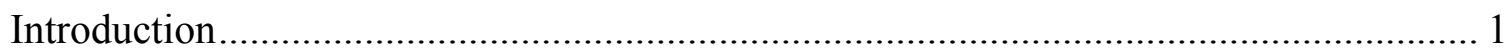

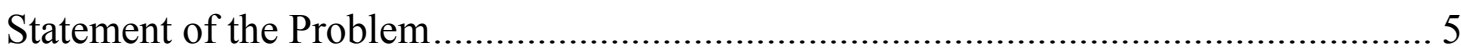

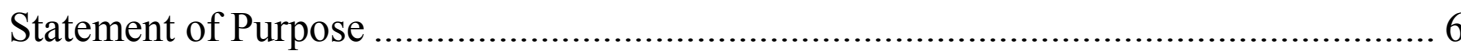

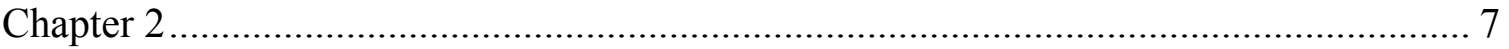

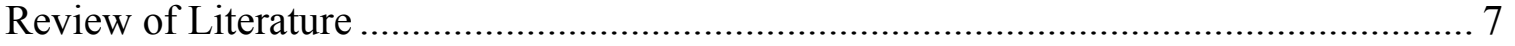

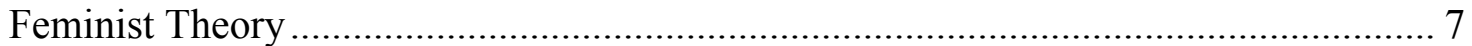

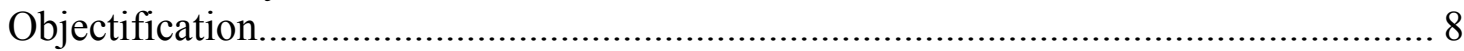

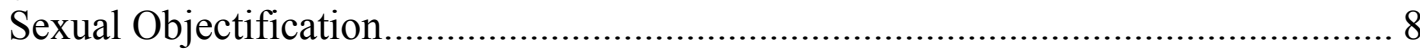

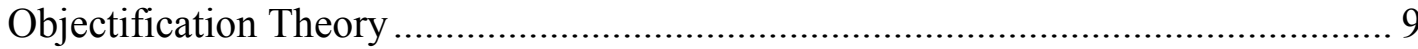

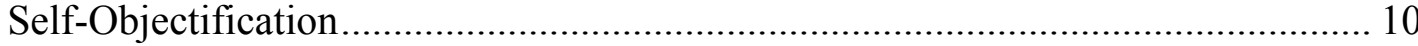

Psychological consequences of self-objectification.............................................. 11

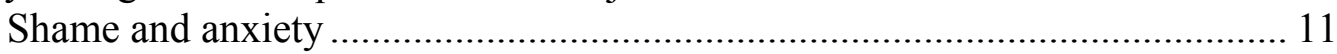

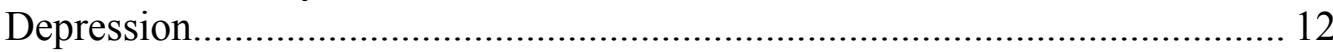

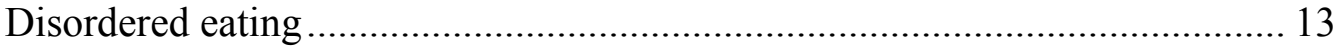

Cognitive consequences of self-objectification .................................................. 14

Disrupts peak motivational states and thought processes................................. 14

Reduced Motivational States ..................................................................... 14

Physical consequences of self-objectification .................................................. 15

Reduced Motor Performance ……………………………......................... 15

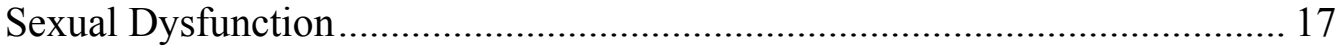

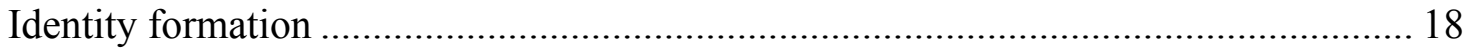

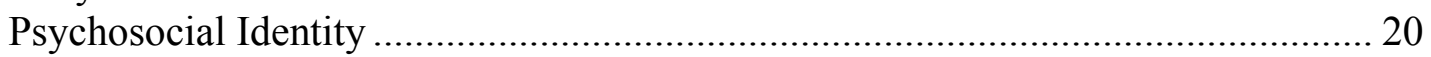

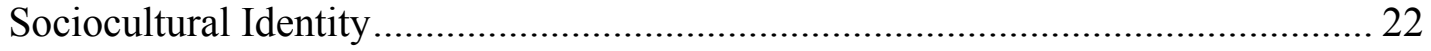

Constructed versus Conferred Identities ............................................................... 23

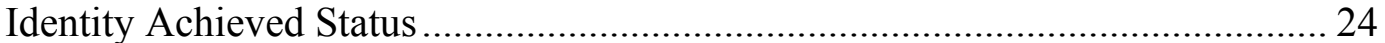

Identity Moratorium Status ................................................................................ 25

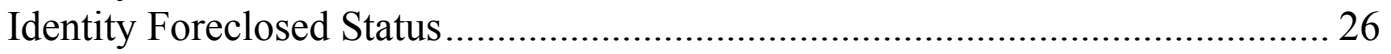

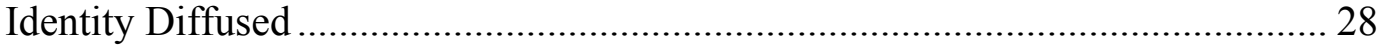

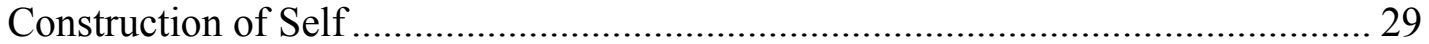

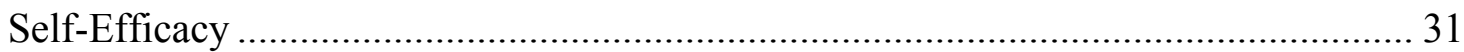

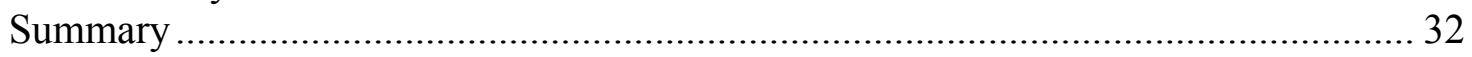

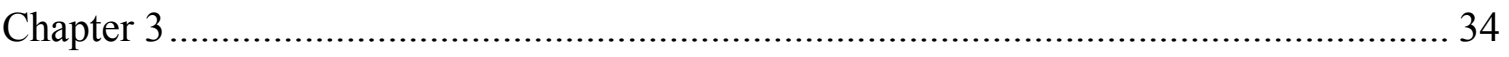




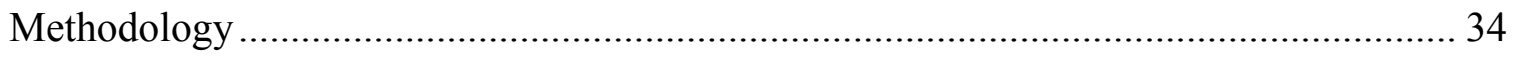

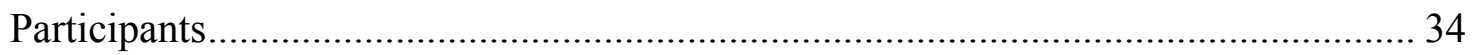

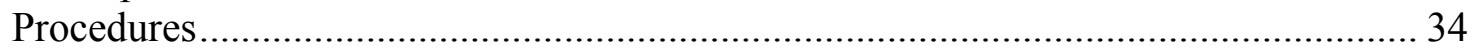

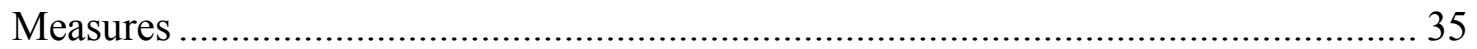

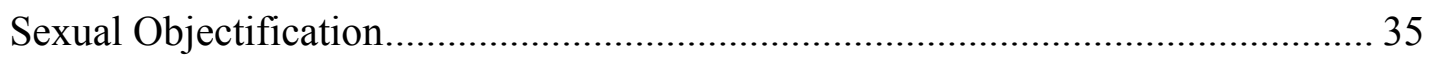

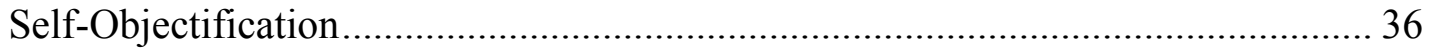

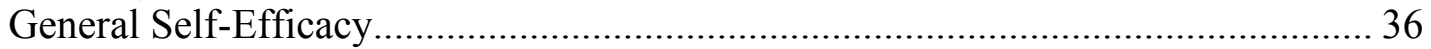

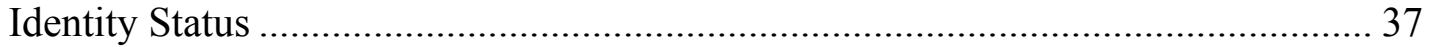

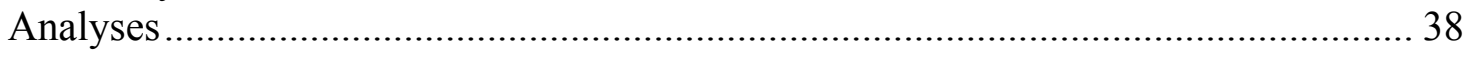

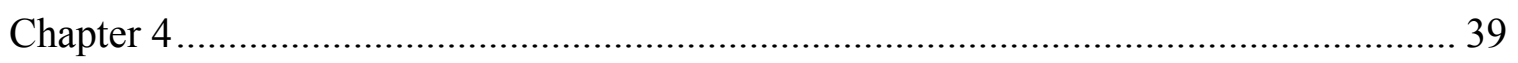

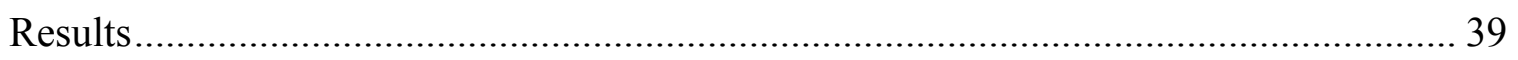

Analysis 1 - Identity Achievement ....................................................................... 43

Analysis 2 - Identity Moratorium....................................................................... 43

Analysis 3 - Identity Foreclosure ………………………................................. 43

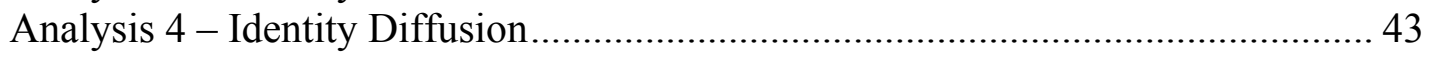

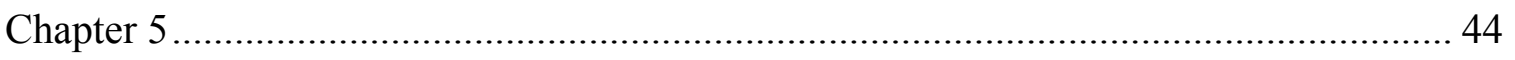

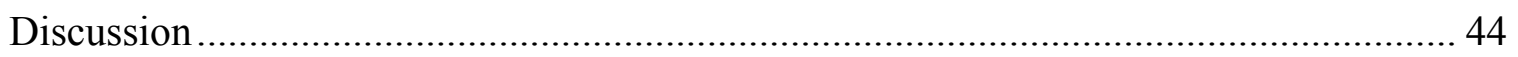

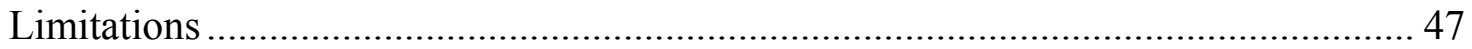

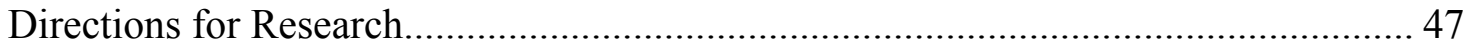

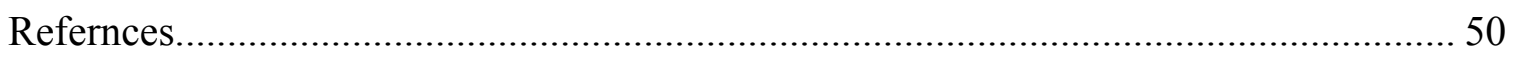

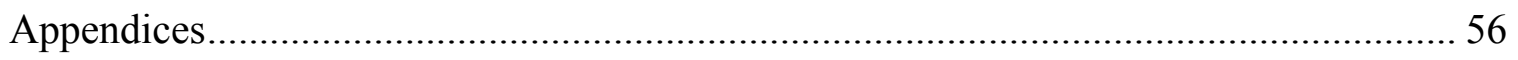

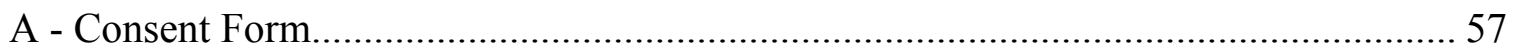

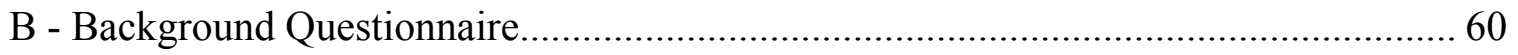

C - Sexual Objectification Questionnaire - Women....................................................... 62

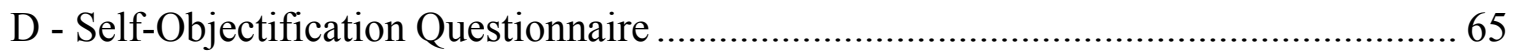

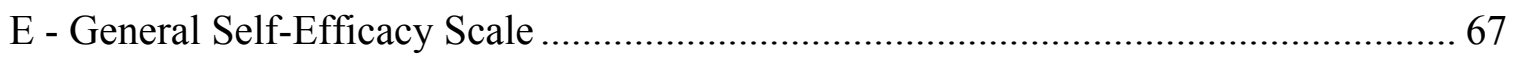

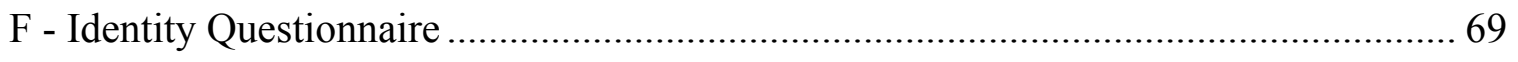

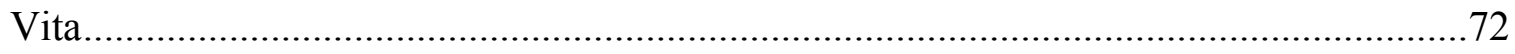




\section{LIST OF TABLES}

Page

Table 1 - Correlations for Self-Efficacy, Self-Objectification and

Sexual Objectification................................................40

Table 2 - Correlations for Self-Efficacy, Self-Objectification, Sexual Objectification (Predictor Variables) and Identity Achievement, Moratorium, Foreclosure and Diffusion.................................41

Table 3 - Hierarchical and Stepwise Regression Analysis for Identity Achievement, Identity Moratorium, Identity Foreclosure and Identity Diffusion According to Self-Efficacy, Self-Objectification and Sexual Objectification.....................................................42 


\section{CHAPTER 1}

\section{INTRODUCTION}

Socialization patterns of boys and girls contribute extensively to gender differences in contemporary western society. Such differing socialization processes have contributed to the imbalance of power and social status afforded to men and women (Fredrickson \& Roberts, 1997). One form of socialization which results in gender status discrepancy that occurs in western society is sexual objectification, specifically that of the female body. As a type of gender oppression, sexual objectification is the experience of being valued for the use and consumption of one's body or body parts (Fredrickson \& Roberts).

Exposure to sexual objectification begins at very early ages and continues through the life span as most Americans have continual access to the tools (especially the mass media) used in perpetuating this message. The paradigm of females being valued for their body is prevalent and pervasive in almost all forms of mass media including television, movies, music videos, and beauty magazines in which the camera lens is frequently focused on specific female body parts (Mulvey, 1975) which are often scantily clothed, tightly clothed, or not clothed. Sexual objectification is also experienced more directly via person to person in objectifying interactions.

Along with its negative effects on social status and power, sexual objectification can have more personal or internal negative ramifications for girls and women (Cusumano \& Thompson, 1997). One consequence outlined by Fredrickson and Roberts (1997) is self-objectification, or adopting an observers' view of the self and treating the self as an object to be looked at and subjugated to evaluation. Research shows that 
reducing the self to an object is related to several psychological, behavioral and cognitive consequences including shame, anxiety, increases in mental health risks (Calogero, 2004; Calogero, Davis \& Thompson, 2005; Fredrickson, Roberts, Noll, Quinn \& Twenge, 1998; Muehlenkamp \& Baglama, 2002; Slater \& Tiggeman, 2002), decreases in motivational states (Gapinski, Brownell, \& La France, 2003), diminished physical performance (Fredrickson \& Harrison, 2005) and diminished cognitive functioning (Gapinski, Brownell, \& La France; Fredrickson, Roberts, Noll, Quinn \& Twenge) (see Fredrickson \& Roberts).

One question of interest in this study concerned how both sexual objectification and self-objectification related to the identity formation of females. Although a lifelong process, identity formation culminates during the period of adolescence as it is during this life phase that self-definition becomes increasing salient (Kroger, 1989). Because identity formation does not occur in an individual vacuum, but in a social or environmental context, Erikson (1968) further explained identity formation as a psychosocial process: "a process 'located' in the core of the individual and yet also in the core of his communal culture" (p. 22, Erikson's italics). In their attempt to self-define, adolescents examine who they are and what they are all about in addition to being faced with many new roles involving social realms such as romance and vocation (Kroger, 1989). It is during this time of role exploration and experimentation that crisis occurs. The individual must begin to decide, or resolve, which roles are appropriate and incorporate these into her definition of self. Thus, cultural structure and its ideologies are essential because "without an ideological simplification of the universe the adolescent ego cannot organize experience according to its specific capacities and its expanding involvement” (Erikson, p. 27). 
Cultural norms and social mores provide this simplification by prescribing expected attitudes and behaviors. Therefore, the phenomenon of sexual objectification as a socializing factor along with its consequences of self-objectification should, in part, affect identity formation. However, research in this area is lacking; therefore, this study attempted to examine the relations between sexual objectification, self-objectification, and identity formation in adolescents.

Identity formation, or the way in which one resolves the identity crisis, contains two dimensions: exploration and commitment (Erikson, 1950, 1968; Marcia, 1966). Exploration can be viewed as one's level of actively seeking out and sorting through those factors (attitudes, values, behaviors, roles) which may or may not be incorporated into one's self-schema. Commitment is the level at which the individual is dedicated to those factors which she has incorporated. A combination at varying levels of these two dimensions can result in one of four statuses: identity achievement, identity moratorium, identity foreclosure, and identity diffusion (Marcia, 1966; 1980; 1994). Identity achieved individuals are those who have experienced crisis, explored alternatives, and have made a commitment (personal investments in who one is). Identity achieved is considered the optimal identity status. Individuals in a state of identity moratorium are experiencing a crisis and exploring alternatives, but have yet to make a commitment. Foreclosed individuals are those who have made a commitment without experiencing a crisis or exploring alternatives. Identity diffused individuals are those who have not experienced a crisis, have not explored meaningful alternatives, or made any identity commitments. Attaining an optimal identity status requires the individual to become an active agent. Therefore, the identity status of an individual should also show a relation with the 
individual's level of self-efficacy. Self-efficacy pertains to the belief in one's own capabilities to produce desired effects (Bandura, 1997). Bandura claimed that people will only attempt to make things happen (behave in particular ways) if they feel they have the power to produce results. Consequently, self-efficacy should also be correlated with identity status; specifically, an individual will attain, or will attempt to attain, a particular status only in accordance with how capable she feels in her ability to explore opportunities and alternatives and produce desired results, in this case identity achievement and moratorium. In other words, an individual will only successively explore her options pertaining to her identity if she feels capable of doing so. This study attempted to explore the relationship between self-efficacy and identity development.

Socialization factors such as sexual objectification, and its consequence of selfobjectification, may also be related to self-efficacy. As a gender discourse, sexual objectification attaches a value on female body parts with the value increasing as the body comes closer to meeting the social ideal. With a woman's value being linked to her body, is it plausible that a body with a higher value would result in increased feelings of self-efficacy? Or, perhaps women with higher feelings of self-efficacy strive to attain the cultural ideal of the female body with more success than those who have lower efficacy beliefs? Or, can being sexually objectified hinder development of self-efficacy because value is being placed on beauty, not competency. Because this study is not experimental, no causal statements will be made about objectification and self-efficacy. However, an association between the two variables will be explored. 


\section{Statement of the Problem}

The development of self-identity is both a social and cognitive construction (Harter, 1999). The personal self develops in the context of interpersonal relationships and socialization factors, which communicate values, standards, and norms of the culture at large. As the individual experiences and internalizes the feedback from significant individuals and messages of the cultural norm, a cognitive process of self-representation and self-perception begins to take place. A component of this cognitive process is social comparison (Festinger, 1954). Upon internalizing the messages from social factors, the individual will begin to make judgments and values concerning the self by comparing the self with the social ideals expressed by social others. When the social ideals are unattainable, the individual may develop feelings of incompetence and lowered selfworth, perhaps resulting in negative consequences for identity development.

When a culture promotes gender oppressive messages, such as the sexually objectifying messages promulgated by American culture, positive identity formation is likely to be hindered in the oppressed sex. A culture of sexual objectification clearly tells girls and women that they are valued first and foremost for their bodies, with the value increasing for those more closely attaining the cultural ideal. It appears through even casual, perusal of media in America that the female cultural ideal equates to being tall, thin, small waisted, and large breasted. Because this physical attainment is unlikely to be achieved by the majority of females, the consequences may be staggering low levels of self-competency, resulting in less than optimal identity formation. 


\section{Statement of Purpose}

The purpose of this study was to examine if relationships exist between objectification, self-efficacy, and identity formation. First and foremost, this study examined whether a correlation indeed existed between sexual objectification and selfobjectification. Secondly, the study examined the predictive role of the independent variables (self-efficacy, self-objectification and sexual objectification) and their contributions to the identity statuses. More specifically, the following hypotheses were explored.

H1: Sexual objectification would be significantly and positively correlated with selfobjectification.

H2: Self-efficacy would be highly correlated with and predictive of all four identity statuses. The relationship between self-efficacy and achievement and moratorium will be positive. The relationship between self-efficacy and foreclosure and diffusion would be negative.

H3: Self objectification and sexual objectification would add to the prediction of identity moratorium, foreclosure and diffusion after statistical adjustment was made for selfefficacy. 


\section{CHAPTER 2}

\section{REVIEW OF LITERATURE}

This chapter will begin by giving a brief overview of feminist theory. It will then review articles and literature pertaining to the four variables considered in this study. The first construct to be reviewed is sexual objectification according to objectification theory. Next, the review will cover self-objectification and present empirical investigations on several psychological, cognitive and physical consequences of self-objectification. Identity development will then be explained in both psychosocial and sociocultural terms, with a detailed description of the four identity statuses. Finally, self-efficacy will be defined and explained.

\section{Feminist Theory}

Feminist thought has its roots in the social movement of the 1960s and 1970s and has continued to evolve over the next thirty years to present. Because of the variety of agendas coming out of that movement, many perspectives are encompassed by feminist theory and a uniting definition can be difficult. However, feminist theory in general examines gender perceptions, gendered behaviors, and the inequalities associated with gender (Chibucos \& Leite, 2005). From this perspective, gender is considered socially constructed and stems from the different expectations for males and females. These expectations pertain to a variety of domains including behaviors, values, and attitudes.

One goal of feminist theory is to empower women by informing them of the gender discourses being enacted by society and encouraging change in the social structure that supports such discourses. One feminist theorist defined feminist theory as "an analysis of women's subordination for the purpose of figuring out how to change it" 
(Gordon, 1979). Therefore, feminist theory not only examines gender differences and inequalities, but takes a proactive stance to change social conditions that create and perpetuate women as a disenfranchised group in society.

\section{Objectification}

\section{Sexual Objectification}

Sexual objectification is the occurrence of being treated merely as a physical body, or as a collection of body parts, to be viewed, evaluated, used and consumed by others (Fredrickson \& Roberts, 1997). Bartky (1990) argued that when sexual objectification occurs, a woman's personhood is separated from her body parts and/or sexual functions and she is reduced to the status of mere instruments, to be used for the pleasure of others. This overvaluation of her body devalues her other attributes, such as her thoughts and feelings; it devalues who she is. In other words, who she is becomes secondary to what she is. Bartky also asserted that sexual objectification is oppressive in nature; it is something that is done against women as it occurs independently from what women want. In this respect it can be viewed as a form of gender oppression; thus, the devaluation of females helps maintain the patriarchal power granted to males by our society, keeping females in a state of subordination. In American culture, sexualization of females by males is sanctioned regardless of its devaluation of girls and women, and in turn helps maintain the male dominant paradigm in our society.

Sexual objectification is rampant in American society. Its insidious message can be seen and heard throughout America, with mass media its prime outlet. Evidence shows that prime time television, for example, contains more frequent sexual comments aimed towards women as compared to men, particularly focusing on breasts (Grauerholz \& 
King, 1997). Television advertisements frequently depict women as sex objects (Lin, 1998), as do music videos (Tiggemann \& Slater, 2004) and fashion and beauty magazines (Merskin, 2004). Considering that American households generally contain a number of television sets, the bombardment of sexually objectifying messages has a clear and open path into the lives of families and its individuals. Aside from mass media, women are sexually objectified in their everyday experiences via cat-calls, sexual gazing, and overt sexual comments and harassment.

Because of the pervasive nature of sexual objectification, objectification theory has been proposed by Fredrickson and Roberts (1997) to provide a framework for understanding its impact on women's daily experiences. According to objectification theory, both overt (whistling, cat-calling, sexual gazing) and covert (media images, advertising) sexual objectification of the female body produces negative consequences for women. Although not all women will have the same responses and levels of objectification may vary, objectification theory proposes that the fundamental psychological consequence of sexual objectification is self-objectification.

\section{Objectification Theory}

Sexual objectification places an inordinate amount of emphasis on the female body, its physical attributes, and continually sends the message to girls and women that they are being viewed and evaluated for their bodies (Fredrickson \& Roberts, 1997). Very young girls are exposed to the message that their value lies in their bodies and their beauty, and this continues throughout her life span. Therefore, as an adaptive behavior, girls and women respond by habitually evaluating themselves. Although sometimes viewed as vanity, this behavior may actually be the result of internalizing the cultural 
expectations of female beauty and continually monitoring whether or not the self is meeting these expectations. However, the energy devoted to body monitoring is energy directed away from other areas of development, such as cognitive, emotional, spiritual and mental. Therefore, maintaining the high value placed on physical attributes oppresses the female, further reinforcing patriarchal society and the power inequity within it.

\section{Self-Objectification}

The primary consequence of sexual objectification outlined by Fredrickson and Roberts (1997) is that its subtle message cajoles girls and women to adopt a third party view of themselves, termed self-objectification. In other words, girls and women take an outsider's perspective of themselves; they begin to treat themselves as if they were objects. They view themselves not in an incorporated "whole person" manner, but in a disconnected fashion as if their body was separate from the self. This disconnected view of the self can be conceptualized using James' I-self, Me-self model. The I-self, or self as subject, can be viewed as the actor or knower. It includes constructs such as selfawareness, self-agency, self-continuity and self-coherence (Harter, 1999). It is the I-self who constructs the Me-self. The Me-self can be viewed as the object self and includes the material, social and spiritual aspects of self. In self-objectification, the individual begins to construct the Me-self not only from the I-self, but begins to incorporate an observer's perspective in the Me-self construct. This peculiar, self-objectifying view of self-asobject which was not constructed by the I-self naturally leads social scientists to discern the consequences of self-objectification. 


\section{Psychological consequences of self-objectification.}

Shame and anxiety. Fredrickson and Roberts (1997) have found that women who self-objectify chronically monitor their physical selves in anticipation of others' reactions. This habitual body monitoring includes self-evaluations by comparison to the cultural ideal. Because western culture has created a female body ideal which is unattainable for most, the average American women is likely to feel that she fails to measure up (Groesz, Levine, M.P., \& Murnen, S.K., 2002). Consequently, empirical studies have shown that this lack of convergence of the physical self with the internalized ideal physical self, along with the feelings of failure, will invariably lead to feelings of shame (McKinley, 1998). As explained by Fredrickson and Roberts, this shame arises from a "fusion of negative self-evaluation with the potential for social exposure" (p. 181). The lack of convergence between the real and ideal physical selves can also lead to feelings of anxiety (Noll \& Fredrickson, 1998) and an intense desire to escape and hide, accompanied by feelings of worthlessness (as cited by Fredrickson \& Roberts).

In a study conducted by Calogero (2004), results indicated that when women merely anticipated being objectified by men via male gazing, it produced greater feelings of self-objectification and body shame. This demonstrated that women will self-objectify and feel body shame in a non-body-focused situation and without actually being sexually objectified. So ingrained and internalized are the negative emotions to sexual objectification that one merely has to imagine being in an objectifying situation in order to produce its damaging reactions.

Not only can anticipation of being sexually objectified increase selfobjectification and body shame, but Fredrickson, Roberts, Noll, Quinn and Twenge 
(1998) found that self-objectification increased feelings of body shame. Observing 72 females who were subjected to a state of self-objectification (trying on a swimsuit), Fredrickson et al. found that objectification contributed significant variance in predicting body shame. Similarly, Johnston (1997) has found that self-objectification is correlated with appearance obsession, which is described as "the chronic, painful preoccupation with one's physical appearance. He states that "it creates never-ending frustration through significant internal pressures to meet unrealistic beauty standards and important goals of perfection" (p. 63), thus resulting in shame. In addition to these resultant feelings of shame, researchers have concluded that shame can generate intense feelings of powerlessness and worthlessness (Fredrickson \& Roberts, 1997), which can then, in turn, host a myriad of other consequences.

Depression. Several studies indicate that self-objectification contributes to depressive symptoms (Muehlenkamp \& Saris-Baglama, 2002; Noll \& Fredrickson, 1998; Tiggemann \& Kuring, 2004). Tiggemann and Kuring have found that the accumulation of self-objectification, body shame, body anxiety, body appearance apprehension and decreases in motivational states combine to create depression. Fredrickson and Roberts (1997) explained that, because the feelings of body shame and anxiety are not easily surmountable, combined with unattainable societal beauty standards, the result is an uncontrollable state for the individual. This, in turn, leads to depression. Similarly, Muehlenkamp and Saris-Baglama offered the suggestion, that the link between selfobjectification and depression lies in the anxiety and powerlessness that women feel as a result of not knowing when they will encounter objectification. They proposed this anxiousness and lack of control contribute to depression. They also explained that the 
link between self-objectification and body dissatisfaction contributes to feelings of depression. In corroboration, McKinley (1998) also found that self-objectification is associated with body dissatisfaction and researchers have well documented the link between body dissatisfaction and depression.

Disordered eating. Perhaps the most documented consequence of selfobjectification is disordered eating (Daubenmeir, 2005; Greenleaf, 2005; Moradi, Dirks, \& Matteson, 2005; Muehlenkamp \& Baglama, 2002; Slater \& Tiggemann, 2002). In an earlier study, Noll and Fredrickson (1998) found that not only was the relationship between self-objectification and disordered eating mediated by body shame, but that a direct correlation existed between self-objectification and disordered eating. This direct path may indicate that anticipated body shame (see above) motivates self-objectifying women to develop eating disorders to avoid body shame. This suggests that selfobjectification and its negative consequences can occur regardless of one's satisfaction with one's appearance (Fredrickson \& Roberts, 1997).

Muehlenkamp and Baglama (2002) also found an association between selfobjectification and disordered eating. Exploring the role of internal awareness and its potential for mediating the relationship between self-objectification and disordered eating, they found no mediator effect. Again, a direct relationship was found. Although self-objectification was found to have a direct relationship with restrictive eating, depressive symptoms mediated the relationship between self-objectification and bulimic symptoms. 


\section{Cognitive consequences of self-objectification}

Disrupts peak motivational states and thought processes. Self-objectification has been indicated with negative psychological impact and there is mounting evidence that it disrupts cognitive processes. A consequence outlined by Fredrickson and Roberts (1997) is that self-objectification prevents peak motivational states. The prevention of a peak state occurs when a woman's thoughts and actions are interrupted when attention is called to her body, both in its appearance and its functions. Many women can testify as to how their thought processes get distracted when having an objectifying experience, but Fredrickson, Roberts, Noll, Quinn and Twenge (1998) have taken this a step further. They conducted an experiment and found that when women were manipulated into a state of self-objectification, their math performance declined, indicating that selfobjectification does tax a women's resources and disrupt mental performance. Researchers believe that the self-conscious appearance monitoring induced under the experimental conditions caused a disruption in the individual's stream of consciousness and thereby limited mental resources for other activities, including mathematical applications.

Reduced Motivational States. In order to accomplish challenging and difficult tasks, a person must reach a motivational state characterized by full absorption in the activity, i.e., intense concentration. Many find experiencing this level of concentration enjoyable and rewarding as it provides for an optimal experience (Fredrickson \& Roberts, 1997). Csikszentmihalyi (1990) calls this "flow", and argues that increasing these types of experiences can improve the quality of life. He also argued that flow states are not passive moments, but something the individual makes happen, indicating the exercise of 
personal agency. Experiencing high flow states may influence feelings of well-being and purposefulness, which suggests a myriad of implications as well-being contributes to one's sense of self-esteem and self-worth. Flow also helps "integrate the self" because the intense concentration it requires forces the individual's thoughts, feelings and intentions on a shared goal (Csikszentmihalyi, p. 41).

Researchers have suggested that one consequence of objectification is a reduced motivational state; in other words, a reduction of flow. Gapinski, Brownell, and LaFrance (2003) conducted an experiment which induced a state of objectification in its female participants. To evaluate the effects of self-objectification on motivation, they asked eighty women, ages 17 to $21(M=18.69)$, to either try on a swimsuit (high objectification) or a sweater (low objectification), under the guise of participating in a consumer behavior and emotion study. They were then required to complete a questionnaire which included measures on self-objectification, anxiety and negative emotions, intrinsic motivation, self-efficacy and cognition. Questionnaires were completed before changing back into their own garments. When analyses were conducted for the performance related measures, results indicated that lower self-objectification was significantly associated with higher intrinsic motivation. Clothing condition had no main effect on motivation. This suggests that women who generally self-objectify to a greater extent may be less likely to experience peak motivational states, regardless of their environmental context.

Physical consequences of self-objectification

Reduced Motor Performance. Objectification theory posits that girls and women may experience reduced motor performance as a result of self-objectification 
(Fredrickson \& Roberts, 1997). Feminist philosopher Iris Young (1990) first approaches this idea in her essay "Throwing Like a Girl” in which she describes how habitual body monitoring reduces the flow of a woman's physical activity. She contends that physical movement draws external attention to the body thereby increasing the potential for objectification. Consequentially, the woman begins to self-objectify during physical activity, which divides her attention between what her body looks like and the task she is trying to accomplish. Because a portion of her attention is drawn away from the task she is trying to accomplish, her motor performance is reduced.

To put this idea to the test, Fredrickson and Harrison (2005) conducted a study involving 202 girls, ages 10 to $17(M=13.17)$. Participants completed a questionnaire packet measuring sports participation and trait objectification. One week later, the same participants completed a written measure on state objectification, followed by a performance test. For the performance test, they proceeded to a gymnasium where they were instructed in a throwing task. Each girl was to throw a ball three times while being video taped. After the throwing task, each participant completed two questions concerned with thoughts while throwing. The throwing performance was coded by an advanced kinesiology student and measured five distinct components of throws: backswing action, trunk action, humerus action, forearm action, and stepping action. Hierarchical linear regressions were performed to test their hypothesis that self-objectification would predict motor performance. Congruent with objectification theory, the results showed that selfobjectification predicted significant variance in throwing performance. Girls who exhibited greater self-objectification exhibited poorer throwing performance. 
Sexual Dysfunction. Researchers have well documented that women report more dissatisfaction and dysfunction in their heterosexual relations than do men (Fredrickson $\&$ Roberts, 1997). Many arguments have been offered as to the nature of this phenomenon including: (a) the double standard concerning the reputations of sexually active males and females, (b) gender-role stereotypes depicting females as sexually passive, and (c) socially constructed sexual scripts that define sexually aggressive females as being selfish. Another explanation, offered by objectification theory, suggests that the sexual dysfunction experienced by women may be the result of the habitual body monitoring experienced by those who self-objectify, the lack of internal awareness created by objectification, and body shame and anxiety (Fredrickson \& Roberts).

Fredrickson and Roberts (1997) asserted that women who self-objectify pay chronic attention to their visual image, which draws their mental energy away from other activities. During sexual activity, women may become so preoccupied with monitoring their body's image that they mentally disengage from the sexual activity. As a result, they may prevent themselves from full engagement and enjoyment of sexual experiences. Masters and Johnson (1970) referred to this as "spectatoring" and found that this form of monitoring hinders a woman's sexual satisfaction.

To further explore the role of spectatoring during physical intimacy, Wiederman (2000) hypothesized that body monitoring would be correlated with problematic sexual dysfunction. His analyses indicated significant negative relationships between body image self-consciousness and well-being, self-rated body attractiveness, sexual esteem, extent and frequency of heterosexual experience, and sexual assertiveness. A significant positive relationship was found between body image self-consciousness and BMI, body 
dissatisfaction, sexual avoidance due to negative body image, sexual anxiety and sexual avoidance. In further analyses using multiple regressions, body image self-consciousness scores significantly increased the variance found in extent and frequency of heterosexual experience scores, sexual esteem, sexual assertiveness and sexual avoidance.

These results indicate that body image self-consciousness during sexual intimacy with a male partner may have profound negative effects on young women's sexuality, sexual satisfaction and sexual pleasure. Because sexuality, in part, develops in the context of interpersonal relationships and interpersonal relationships are salient to female identity, it stands to reason that process which effect sexuality may also impact identity development.

\section{Identity formation}

Although the process of forming one's identity is a lifelong process, it culminates during adolescence. Erikson (as cited by Paranjpe, 1975) suggested that during the life course, one must navigate a series of turning points that are crucial as they decide the progression or regression of the psychological identity of the individual. Erikson noted that adolescence is the time in the life span crucial to the development of psychosocial identity (Erikson, 1963; Paranjpe). However, although adolescence is viewed as a crucial time for identity development, identity is never gained once and for all. It is constantly lost and regained, although more lasting and more efficient methods of maintenance and restoration are evolved and fortified in late adolescence (Erikson, 1956).

Erikson (1968) defined identity as having a subjective sense of self-sameness along with the continuity of that self-sameness over time. In other words, it is not only knowing the self, but how the self at present was defined and transformed from the self of 
one's past. Kroger (2000) further elaborated, stating that it is the feeling that in various social situations and contexts, one still has the sense of being the same person. Kroger also added that others outside the self recognize this continuity of personality and act in response to "the person they know." Therefore, individual identity does not concern itself with the individual alone, but also includes the social context in which it develops along with the social feedback the individual receives. Because identity is both a personal (selfthought) and a social (other than self) construction (Harter, 1999), a psychosocial and sociocultural model will be used to discuss identity formation.

Adolescence may be crucial, in part, due to the onset of puberty when the individual experiences numerous changes. Hormonal changes, growth spurt occurrence, and changes in body size and proportions necessitate a restructuring of the body's physiological mechanisms. The impact of these changes at the psychological level may pose a threat to the feeling of sameness (Paranjpe, 1975). In addition to bodily changes, the adolescent is also transitioning from being a financially dependent child to being a more economically independent individual. It is during adolescence that many individuals experience their first employment. Lastly, the adolescent must also contend with newfound sexual and gender roles and the expressions thereof (Paranjpe; Kroger, 2000). This learning of adult roles may prove difficult for the adolescent as she strives for continuity of personality. Sexual objectification may further complicate this process for females seeking their identity as it gives females a specific messages about how they are valued (for their body parts or consumption thereof). 


\section{Psychosocial Identity}

Erik Erikson is generally considered one of the foremost researchers in the psychosocial nature of identity development. Asserting that development occurs within the context of three domains: somatic, personal, and social (1968), Erikson (1950) offered two principles which govern his renowned eight stages of human development, including identity development. He alleged that: (a) human beings sequentially develop their sensorimotor capabilities, governed by genetics, which allows for social interaction, and (b) societies uniquely develop their own patterns of interactions (customs) that invite and encourage those capabilities for continued interaction. Using this framework for identity development, Erikson (1968) believed identity formation to be interplay between the psychological and the social, an interaction of self and others. In psychological terms, identity formation is the process of reflection and observation, occurring at all levels of mental functioning. Psychological components of identity include one's feelings, needs, interests, and defenses, "which give one a sense of I that remains the same across time and circumstance" (Kroger, 2000, p. 9). Socially, the individual evaluates and compares himself to what he perceives is the way that others judge him, a judgment based on social beliefs, norms, and values. It is the social milieus one finds herself in that offers opportunities for identity expression.

Erikson (1950) further defined identity as "an accrued confidence that the inner sameness and continuity prepared in the past are matched by the sameness and continuity of one's meaning for others" (p. 261). He elaborated that "identity is experienced preconsciously as a state of psychosocial well-being. Its most obvious concomitants are a feeling of being at home in one's body, a sense of 'knowing where one is going', and an 
inner assuredness of anticipated recognition from those who count." (1956, p. 74). The "inner sameness" discussed by Erikson is consistent with what Paranjpe (1975) described as the cohesive functional pattern that the individual adopts to integrate the many role behaviors that make up one's life. This allows for continuity of function in spite of individual changes. It allows the individual to pull together all the "pieces of me" and form one, whole, cohesive "me."

Paranjpe (1975) viewed psychosocial identity as the primary organizing principle of the personality system which creates psychological unity. He asserted that it "accounts for the unity, self-sameness and continuity of the personality, for the persistence of a pattern throughout the life history of the individual, and for the shared sameness and solidarity of the individual with his community" (p. 36). Paranjpe highlighted the fact that this continuity does not mean that the individual is stagnant, but is allows for the individual to "know who one is when one gets up in the morning" (p. 74). The "selfsameness" he defined is not analogous to unchanging. To the contrary, individuals adopt a variety of ways of relating according to social context and may take on different faces in different social situations. This concurs with James' (1890) idea that a person may have many different social selves. An individual, as an occupant of a variety of social roles, may appear as a different person in each of the situations in which she finds herself in. Although various social situations may require a different set of behaviors or a different 'face', the individual is still recognized as the same person. Part of the identity formation process is the organizing of different social roles so the personality may be integrated and not split (Paranjpe). 


\section{Sociocultural Identity}

Another approach to identity focuses on the role of society and its contributions to the individual in her process of self-construction. From this orientation, contexts and environment, including relationships wherein language provides the primary means for the formation of the self, help account for the process of self-definition. Therefore, from this perspective, identity is viewed as the outcome of societal possibilities and limitations afforded to the individual within a given context (Kroger, 2000). Using a reciprocal representation, one's identity is shaped by the interactions between one's social context and feedback from others. The identity (self) interacts with society, providing stimulus to its members who will provide feedback, thereby contributing to defining and refining the identity. As the individual interacts with society, she is providing stimulus for other individuals, thereby contributing to their identity formation processes. Thus, both individuals and society are participants in the complex balance of mutual recognition and response, key factors of the process of identity formation. Accordingly, changes in identity are viewed as changes in culturally defined roles and statuses. These social roles and status changes are a response to the individual's changing biology and social learning (Kroger, 2000), as social roles and expectations will change for the individual as she matures.

The role of society and culture cannot be underestimated in the identity formation process of its youth. Kroger (1989) stated that "for late adolescents, the transition from the established norms and social networks of the school, which has given a structure and framework to one's life since earliest childhood, to a frameless post-school world of unknown futures with multiple possibilities, is a daunting one" (p. 93). The attitudes and 
behaviors of youthful members of a society are regulated, in part, by the cultural context. This cultural influence may be overly operative in its transmission of values and may not ultimately serve the best interest of adolescents seeking self-definition (Kroger, 1989), as in the case of sexual objectification. Sexual objectification can be viewed as predetermining women's roles as a sexual object. Kroger stated that society needs to not predetermine roles to allow for the exploration and experimentation required for optimal identity development.

\section{Constructed versus Conferred Identities}

According to Marcia (1966), there are four different identity statuses: (a) identity achieved, (b) identity moratorium, (c) identity foreclosed and (d) identity diffused. Identity achieved and moratorium are considered constructed identity statuses; the individual is an active agent in her own identity development. These statuses are characterized by self-initiated and self-directed seeking and exploration behaviors and processes that are undertaken by the individual to help her determine who she is. These individuals have a sense of having participated in who they become. Marcia states, "they know not only who they are, they know how they became that, and that they had a hand in the becoming" (p. 8).

To the contrary, the latter two identity statuses, foreclosure and diffusion, are considered conferred statuses. Those with conferred identities experience their future as the fulfillment of expectations (Marcia, Waterman, Matteson, Archer, \& Orlofsky, 1993). Instead of undergoing the process of self-exploration and definition, they either conform to the dictates of others (foreclosure) or disengage from the process altogether (diffuse). Conferred individuals do not actively seek out "who they are" or engage in the process of 
defining themselves. They simply become who others expect them to be or detach from the identity formation processes entirely.

\section{Identity Achieved Status}

The identity achieved status is generally perceived as the most favorable of the four statuses. Achieved individuals are those persons who have identities which have been self-constructed via self-initiation, resulting in an internalized sense of self. These individuals are active participants, engaging all domains of functioning (i.e., cognitive, emotional, psychological) in who they become. Although committed to the identity they have constructed, they have "game plans" for their lives which are flexible and subject to revision (Marcia et al., 1993) and their future is viewed as something that is to be created and shaped; a time of reflection and realization. This self-directed approach to identity development has several positive outcomes for the individual.

In research conducted concerning youths in American culture, identity achieved persons scored consistently higher on autonomy measures as their decision making processes were less reliant on others' opinions (Kroger, 1989). Decision making becomes a central tenet intertwined with who they are and who they become; they tend to be free thinkers, gauging their life's path according to their own plan. Achieved individuals also tend to have high levels of ego development and self-esteem (Kroger, 2000). This should come as no surprise as autonomous decision making will naturally lead to feelings of competence and increased levels of self-esteem. Relative to cognitive capacities, research has indicated that identity achieved individuals are creative (adaptive) and function well under stress, most frequently at the highest level of post-conventional moral reasoning (Kroger). They are likely to think reflectively and productively, possessing sophisticated 
critical thinking skills. Again, this intuitively makes sense; unencumbered decision making skills along with high levels of competency can certainly result in creative, productive functioning.

Socially, identity achieved persons are reported as being well liked, perceived as knowledgeable and intelligent, and were overall viewed as well adjusted (Kroger, 2000; Marcia et al., 1993). This may be due, in part, to their effective communication skills as identity achieved adolescents report open and active communication with their families (Marcia et al.). Perhaps the communication techniques practiced with family members are also utilized in their other social relationships. However, achieved individuals are not merely engaging in socially acceptable behavior and "nice talk" to be conforming. In interactions with others, achieved persons will use assertive social influence techniques, thereby risking disapproval from others (Marcia et al.). Honest expression of the self takes precedence over mere conformance. This ability to confidently express the self may impact the quality of the interpersonal relationships that achieved individuals develop as research indicates that they are more secure in their attachment patterns (Kroger, 1989).

\section{Identity Moratorium Status}

Moratorium status is best reflected in those individuals, who in the process of synthesizing internal structures, are constructing their identities (Marcia et al, 1993). Not committed to any identity status thus far, they are actively searching and exploring options as opposed to relying on those conferred by immediate others. Their willingness to explore alternatives is characteristic of their high levels of openness to new experiences (Kroger, 2000). Because individuals in this state are actively seeking new experiences, they may be deemed more unstable than their achieved counterparts. 
However, moratorium is a required step in the progression of attaining an achieved status. In other words, one can only attain an achieved identity status upon completion of a moratorium.

Those in a state of moratorium tend to be highly anxious as they are making themselves vulnerable to new experiences, but appropriately use denial and projection as a means to control their anxiety (Kroger, 2000). Their ability to control their anxiety in this manner may be indicative of their cognitive complexity, which is on par with identity achieved individuals. In a similar manner to achieved persons, moratorium individuals tend to display high levels of moral reasoning and engage in sophisticated decision making processes, not simply relying on the opinions and judgments of others (Kroger, 1989). They are utilizing their resources (eg.- cognitions, emotions) in their exploration process to lay the path to who they are.

Because exploration processes induce an unsteady state, it stands to reason that their interpersonal relationships are unsteady as well. It is indicated in research that those individuals in a state of moratorium tend to have intense and volatile relationships and avoid commitment (Kroger, 1989). Although turbulent, this is congruent with the state they are in and should be viewed as normative. Moratorium individuals will avoid commitment with others if they have yet to achieve commitment (identity) with themselves (Kroger, 1989).

\section{Identity Foreclosed Status}

Identity foreclosed individuals are those persons who have committed to an identity without adequately exploring available options, instead turning to identities that were prescribed by others. Marcia et al. (1993) describes this as adopting a lifelong 
"game plan" that was laid out for them by someone other than the self, most often by authority figures such as the parents. However, their game plan is also culturally influenced by strong social sanctions, such as those that may prescribe gender construction and sexual objectification. Living up to prearranged standards and ideals is what the future holds for these individuals (Marcia et al.). For those females who are succumbing to the messages of sexual objectification (prearranged standards), they will internalize that their value lies within their body. Accepting this standard without exploring other options may lead the woman down an identity path that is wrought with self-doubt and low esteem since the beauty ideal is virtually unobtainable in American culture. Research has shown that identity foreclosed individuals' self-esteem is contingent upon the extent to which they "fulfill" the tasks given them.

Research has shown that cognitively, foreclosed individuals use less complex reasoning styles (Kroger, 1989). More specifically, Read (as cited by Marcia et al., 1993) found that foreclosed women perceived themselves to be less analytical, less philosophical, and less able to integrate ideas from multiple perspectives. This perception of lacking critical thinking skills may be indicative of the low self-esteem and low selfefficacy that characterizes foreclosed individuals. Or, perhaps, it is deficient critical thinking skills, which induces foreclosure. Without the necessary cognitive ability, exploration is less likely to occur and one is more likely to prescribe to others' ideals.

Researchers have concluded that socially, foreclosed persons are "well-behaved" and placid and are drawn to the values of an authoritarian leader who can show them the right path to follow (Kroger, 1989). They placidity makes them natural followers. However, they do become authoritarian themselves as they are unwavering in their 
opinions, particularly those concerning ideological issues. Being content in who they are, they may appear to be happy and the least anxious among the different identity statuses, but it is due to their unwillingness to question their commitments (Marcia et al., 1993).

\section{Identity Diffused}

Identity diffused persons are those who are lacking a coherent identity. Because they have no firm identity, they are, in a sense, defined by their circumstances (Marcia et al., 1993). These individuals have not actively engaged in forming their identity and have not taken part in the exploration process; they are disengaged from the process altogether. Consequently, because they have no core sense of self, they are vulnerable to the changes of their circumstance and feel somewhat out of control of their futures (Marcia et al.). Accordingly, Kroger (2000) described late adolescents who are diffuse as having low self-esteem, low personal autonomy and ego development, and using an external locus of control.

Socially, diffused individuals are shy and withdrawn (Kroger, 2000; Marcia et al., 1993) and have difficulty in making commitments. They were more likely to view their families as distant and rejecting; more specifically, they view their same-sexed parent as non-accepting and non-emulatable and report being disconnected from both parents (Marcia et al., 1993). This disconnection may extend to other social relationships as they are also most likely to be labeled as uninvolved and isolated, distant and rejecting (Kroger, 1989) and were least liked and generally evaluated lowest (Marcia et al.). If disconnection occurs at the broadest level - e.g. being disconnected from the culture at large, socially sanctioned ideals may be rejected at some level. However, a rejection of cultural ideals and values without exploring suitable values for the self leaves the 
individual in a state of diffusion; a state in which identity construction has not taken place. Construction of self is highly dependent on cultural influences and cognitive input concerning those influences.

\section{Construction of Self}

The self is both a cognitive and social construction (Harter, 1999). The cognitive dimension tends to proceed according to normative developmental change and will allow for self-construction to take place over a period of time. As a social construction, focus turns to those socialization processes that reflect how interactions impact the evaluative content of self-representations (Harter). The personal self develops in the context of interpersonal relationships, beginning at birth with the primary caregiver. The child begins to claim the appraisals that significant others are perceived to have toward the child, beginning with the definition of one's sense of self. Through internalization, the child comes to own these evaluations (Harter). Additionally, the child will begin to internalize the standards and values of others more distal, including the values of the larger society.

The influence that the broader society and culture have on individual selfconstruction is important. The scripts for behavior and for participation as a good member of society are provided by one's culture (Shweder et al., 1998). Shweder et al. stated that a part of our sense of self develops "through membership in some local cultural community and through a history of symbolically mediated experiences with the practices of that group" (p. 895). These symbolically mediated experiences include cultural stereotypes, labels, patterns of communication, and social practice which will essentially provide limits and constraints for the developing individual. Once self- 
development is viewed from a cultural perspective, it is apparent that what is a "good" self or a "bad" self will vary from culture to culture (Shweder et al).

As mentioned, the attitudes, standards, and values a child receives and internalizes reflect those of the greater society and culture. These invariably include physical appearance and beauty standards. In relation to identity formation and self-construction, special emphasis is placed on the role of perceived physical appearance, because this domain is highly and consistently correlated with one's global evaluations of self (Harter, 1999). Harter explained that the "perceptions of one's physical attractiveness, in relation to the importance that is attached to meeting cultural standards of appearance, contribute heavily to one's overall sense of worth as a person" (p. 13). Accordingly, self-worth and self-esteem will be higher in those who feel they have attained the requisite physical characteristics prescribed by society. Conversely, those who feel they do not measure up to the punishing beauty standards set forth by society will suffer from low self-esteem (Harter). This, however, can be mediated by how central appearance is to one's selfschema. Hence, the process of social comparison and the likelihood of falling short of others can result in developing feelings of incompetence and inadequacy.

Physical appearance is particularly salient for women in our society. They are socialized from an early age that "looks matter." Females internalize not only the value placed on their physical body (attractiveness does equal power), but also internalize the cultural ideal of what their physical body ought to look like. Glamorous women who are extremely thin with large breasts are the current cultural ideal in the United States and researchers have noted that female beauty standards such as thinness have become increasingly unrealistic and demanding for women within the past twenty years (Harter, 
1999). These images of female attractiveness are very punishing and are unattainable by the vast majority of girls and women (Harter). The resulting discrepancy between real and ideal physical selves are of particular importance as failure to achieve one's ideals will result in lower self-worth and lead to negative affective reactions (Harter, 1993). Additionally, society also encourages women to alter their looks via invasive cosmetic surgeries to conform to these narrowly defined cultural stereotypes (Harter, 1999).

Self-efficacy may be a salient factor in self-construction, particularly when cultural beauty standards are incorporated. Whether or not a female believes she can attain the cultural beauty standards may be dependent on her levels of self-efficacy.

\section{Self-Efficacy}

Self-efficacy refers to a person's beliefs in their capabilities to achieve attainments via the organization of specific courses of action (Bandura, 1997) and control over their own functioning (Luszczynska, Gutiérrez-Doña, \& Schwarzer, 2005). It is the belief in one's competence to tackle tasks and to effectively deal with adversity in demanding situations (Luszczynska et al.). However, it does not reflect beliefs about how an individual's actions affect outcomes, such as in locus of control. Rather, it reflects an individual's beliefs about whether one can produce the specific action (Bandura). Along with being action specific, self-efficacy can also be conceptualized in a more global fashion, i.e., an individual's generalized sense of confidence in his or her coping abilities that span a wide range of situations (Schwarzer \& Jerusalem, 1995; Sherer et al, 1982) and may reflect across various domains of functioning (Bandura, 1997).

Because efficacy beliefs have been shown to affect a person's thought processes, motivation levels, and affective states (Bandura, 1997), it can explain a broad range of 
human behaviors (Luszczynska et al, 2005) and is highly predictive of behavior (Bandura). Perceived self-efficacy often predicts the goals people set for themselves (Bandura), thereby raising the question: how salient is it in identity formation? Belief of personal efficacy is the primary factor of human agency. If an individual believes she has no power to produce results, she will not make the effort to make things happen (Bandura). If an individual has low self-efficacy beliefs, will she attempt the processes required to form an identity or attain an achieved identity status? On the other side of the spectrum, highly efficacious people tend to perform more challenging tasks and will often invest more effort into the task at hand; they tend to place themselves in challenging settings requiring exploration of their environment (Luszczynska, et al., 2005). Will this pertain to identity formation as well? It stands to reason that individuals who feel highly efficacious, in spite of cultural expectations, will be more likely to undergo the process of identity exploration/moratorium and eventually commit, thereby attaining, identity achievement.

Another point of interest is whether or not cultural expectations affect feelings of self-efficacy in the individual. In sexual objectification, females are valued first and foremost for their bodies and beauty. This confining cultural message may effect her perceptions of her own self-efficacy.

\section{Summary}

Who people are and who people are destined to become is partly determined by the social circumstances in which they find themselves. We are defined by those around us, both proximal and distal, including the cultural values and messages that are imparted to us. In American culture, the phenomenon of sexual objectification tells girls and 
women that their value lies first and foremost merely in what they look like. This message may affect the identity formation process for adolescent girls. While some may succumb to these messages and develop the belief that what they look like is indeed who they are, others will explore this sentiment and find other values to incorporate into their identity. Yet, some may be so despondent over the predominating message that they will, to some extent, disengage from the identity formation process.

How a young woman's internalization of sexually objectifying messages and their effect on identity formation may be mediated by a sense of self-efficacy. Self-efficacious women may feel empowered to challenge the sexually objectifying social norm, and perhaps engage in alternative identity exploration. They might feel more confident in defying what society tells them about themselves and instead, seek out those values that give them a sense of accomplishment and well-being. Alternatively, those with lower levels of self-efficacy, may internalize sexually objectifying messages and begin to selfobjectify. Buying into the cultural message about their bodies, young women may foreclose their identity to the prescribed norm. Those with the lowest sense of efficacy may not even feel the power to do that. They may just disengage from the process entirely. The gender discourse discussed here may have an impact on self-efficacy levels, i.e., sexual objectification may cause lower levels of efficacy. Or, self-efficacy may mediate the effects of objectification. The sequence is unclear. These speculations are beyond the scope of the present study. The intention of this study is to provide insight into the possible relationships that may exist between sexual objectification, selfobjectification, self-efficacy and four identity statuses. If relations are shown, future research may disentangle some of the causal questions that have been raised. 


\section{CHAPTER 3}

\section{METHODOLOGY}

Participants

Participants were 267 college women, ages 18 through 23, from West Virginia University. The majority of the women were white $(93 \%, \mathrm{n}=247)$ and the minority consisted of 3\% African American $(n=7), 1 \%$ Asian American $(n=3), .5 \%$ Latino $(n=$ 2), $.5 \%$ American Indian $(n=2)$, and $2 \%$ listed Other $(n=6)$. In this sample, $23 \%$ were freshman $(n=61), 24 \%$ sophomores $(n=64), 28.5 \%$ juniors $(n=76), 22.5 \%$ seniors $(n=$ $60)$ and $2 \%$ were graduate students $(n=5)$.

\section{Procedures}

Institutional Review Board approval to conduct this study was obtained on May 23, 2006. Immediately following approval, permission was sought from and arrangements were made with instructors of several courses during summer session and fall 2006 semesters. The summer session courses included classes from counseling, human nutrition and foods, political science, introductory psychology, sociology, and statistics. During the fall semester, four different child development and family studies courses were surveyed. Survey completion took place during normal classroom hours. Prior to students' completion of surveys, a brief verbal summary was given to students explaining procedures for survey completion, emphasizing the voluntary nature of participation. Confidentiality was assured and contact information was given. Participants were required to sign an informed consent form which was attached to the questionnaire packet (questionnaires returned without a signed consent were later discarded). The students had 30 minutes to complete the survey, after which they were dismissed. Upon 
completion, students individually returned surveys to the investigator and consent forms were checked for signatures. If the consent form was signed, it was immediately removed from the questionnaire and placed face down on the table while the completed survey was placed in another pile on the table to assure anonymity. When all students had left the classroom, signed consents and completed surveys were put in a box to be brought to the investigators office and stored in a locked filing cabinet. Those surveys without consent were carried outside the box and immediately destroyed via shredding in investigator's office.

\section{Measures}

Along with a consent form (Appendix A) and background questionnaire (Appendix B), participants were asked to complete the following measures:

\section{Sexual Objectification}

Sexual objectification was measured using the Cultural Sexual Objectification Scale (CSOS; Appendix C). The original scale, developed by Hill (2002), contained 40 items and measured an individuals' experience with cultural sexual objectification, including (a) sexual gaze, (b) sexual harassment, and (c) sexual assault. For the purposes of this study, some sexual harassment and all sexual assault items which were graphic in nature were omitted with permission from the scale's developer. The final measure contained 24 self-report items. Participants rated each item according to how often they have had this experience over their lifetime $(1=$ Never; $6=$ almost all of the time). Scores were employed to provide a continuous value of sexual objectification with higher scores

indicating higher objectification levels. In the current study, this measure demonstrated good internal reliability (Chronbach's alpha $=.89)$. 


\section{Self-Objectification}

Self-objectification was measured using the Self-Objectification Questionnaire (SOQ) developed by Noll and Fredrickson (1998) (Appendix D). The SOQ is a selfreport measure in which the participant rank orders 10 body characteristics from "most important" to "least important" in their contribution to self-concept; five items are appearance related and five competence related. The ranks are then summed and the competence score is subtracted from the appearance score. The total can range from -25 to 25 , with a higher score indicating greater self-objectification. This measure is designed to assess the extent to which the individual views his or her body in observable, appearance-based terms (objectified) or non-observable, competence-based terms (nonobjectified) (Noll \& Fredrickson). The measure has been shown to have sufficient validity, and scores correlate positively with scores on the Appearance Anxiety Questionnaire and the Body Image Assessment (Noll \& Fredrickson). In the current study, internal reliability was adequate $(\alpha=.74)$.

\section{General Self-Efficacy}

Self efficacy was measured with the Self-Efficacy Scale (SES; Sherer, Maddux, Mercandante, Prentice-Dunn, Jacobs, \& Rogers, 1982) (Appendix E). The original selfreport measure contained 23 items in two subscales; 17 items in the General SelfEfficacy subscale and 6 items in the Social Self-Efficacy subscale. For the purposes of this study, only the General Self-Efficacy subscale was used. Items are rated on a 6-point Likert-type scale from strongly disagree to strongly agree; a higher number indicating higher self-efficacy expectations. Continuous values were obtained by summing the scores. The SES score is indicative of one's level of general self-efficacy achieved via 
failures and successes attributed to internal factors (Choi, 2003). The Cronbach alpha reported for the General Self-Efficacy Scale in the current study was good at .87 .

\section{Identity Status}

Interpersonal identity status was measured using the Extended Version of the Objective Measure of Ego Identity Status (EOM-EIS; Bennion \& Adams, 1986) (Appendix F). The original measure contains 64 self-report items; 32 interpersonal items and 32 ideological items. This study incorporated only the 32 ideological items (occupational, philosophical, political, and religious) to which the participant responded using a 6 point Likert-type scale ( $1=$ strongly agree to $6=$ strongly disagree). The EOMEIS assesses the four ego identity statuses (achievement, moratorium, foreclosure, and diffusion), that can be analyzed as a categorical variable or as four continuous subscales. The present study used the scale in the continuous fashion. The achievement scale assesses the degree to which the individual has explored choices and has committed to self-chosen values. The moratorium scale assesses the degree to which the individual is exploring choices, but has not yet committed. The foreclosure scale assesses the degree to which the individual has committed to values and life choices without exploring alternative options. The diffusion scale assesses the degree to which the individual is not actively engaged in exploration and/or commitment (Perosa, Perosa \& Tam, 2002). In the current study, this measure showed good internal consistencies in three of the subscales; achievement, moratorium and foreclosure with $\alpha=.69, .72$, and .77 respectively. The diffusion subscale showed marginal reliability with alpha $=.57$. 


\section{Analyses}

First, two chi-square analyses were performed to determine the proportion of sexually objectified and self-objectifying females in each of the identity statuses. Next, bivariate correlations were performed to determine if significant relations exist between the independent variables (sexual objectification, self-objectification and self-efficacy). Correlation analyses were also performed to determine the relations between the independent variables with the dependent variables (four identity subscales). Finally, a combination of hierarchical and stepwise regressions were performed to examine the predictive roles of the independent variables for each identity status. 


\section{CHAPTER 4}

\section{RESULTS}

Two chi-square analyses were conducted to determine: (a) the proportion of females who feel sexually objectified and (b) the proportion of females who self-objectify in each of the four identity statuses. The first analysis showed that $68 \%$ of identity achieved, $65 \%$ of identity moratorium, $50 \%$ of identity foreclosed, and $60 \%$ of identity diffused females felt sexually objectified. The second chi-square analysis showed that $42 \%$ of achieved, $42 \%$ of moratorium, $62 \%$ of foreclosed, and $48 \%$ of diffused females felt self-objectified.

Next, bivariate correlations were conducted between each of the independent variables and are presented in Table 1. As predicted by the first hypothesis, a significant positive correlation was found between sexual objectification and self-objectification $(r=$ $.258, p<0.01)$. Also found was a significant negative correlation between selfobjectification and self-efficacy $(r=-.369, p<0.01)$. Sexual objectification and selfefficacy were not significantly related. 


\section{Table 1}

Bivariate Correlation Analysis Between Self-Efficacy, Self-Objectification and Sexual Objectification $(N=267)$

\begin{tabular}{|c|c|c|c|}
\hline Variable & Self-Efficacy & Self-Objectification & Sexual Objectification \\
\hline Self-Efficacy & 1.00 & $-.369 * *$ & .047 \\
\hline $\begin{array}{l}\text { Self- } \\
\text { Objectification }\end{array}$ & & 1.00 & $.258^{* *}$ \\
\hline $\begin{array}{l}\text { Sexual } \\
\text { Objectification }\end{array}$ & & & 1.00 \\
\hline
\end{tabular}

** Correlation significant at the 0.01 level

* Correlation significant at the 0.05 level 
Then, a correlation analysis was performed between the predictor variables and each of the four identity statuses. Results are presented in Table 2. A significant positive correlation was found between self-efficacy and identity achievement $(r=.286, p<$ 0.01 , while significant negative correlations were found for identity moratorium, identity foreclosure, and identity diffusion $(r=-.293,-.191$ and $-.271, p<0.01$, respectively). A significant negative correlation was found between self-objectification and identity achievement $(r=-.140, p<0.05)$, and between sexual objectification and identity foreclosed $(r=-.176, p=0.01)$.

\section{Table 2}

Correlation Analysis Between Self-Efficacy, Self-Objectification, Sexual Objectification (Predictor Variables) and Identity Achievement, Moratorium, Foreclosure and Diffusion $(N=267)$

\begin{tabular}{lcccc}
\hline \multicolumn{1}{c}{ Variable } & Achievement & Moratorium & Foreclosure & Diffusion \\
\hline Self-Efficacy & $.286^{* *}$ & $-.293^{* *}$ & $-.191^{* *}$ & $-.271^{* *}$ \\
& & & & \\
$\begin{array}{l}\text { Self- } \\
\text { Objectification }\end{array}$ & $-.140^{*}$ & -.039 & .032 & -.014 \\
& & & \\
Sexual & .076 & -.049 & $-.176^{* *}$ & -.008 \\
$\begin{array}{l}\text { Objectification } \\
\text { ** Correlation significant at the } 0.01 \text { level }\end{array}$ & \\
* Correlation significant at the 0.05 level & & \\
\hline
\end{tabular}


Finally, four hierarchical regressions were conducted to further examine the variance contributed by each of the predictor variables to the four identity statuses (Table 3). Self-efficacy was entered first because of it high correlation with all four identity statuses. Stepwise regression was chosen for the next two steps because it offers the best predictive model where multicollinearity between the independent variables occurs and allows for the elimination of variables that are superfluous (Tabachnick \& Fidell, 1996).

\section{Table 3}

The Prediction of Identity Achievement, Identity Moratorium, Identity Foreclosure and Identity Diffusion According to Self-Efficacy, Self-Objectification and Sexual Objectification $(N=267)$

Variable $\quad B \quad S E B \quad \beta \quad t \quad p \quad s r^{2}$

Analysis 1 - Identity Achievement

$\begin{array}{llllllll}\text { Step 1: Self-Efficacy } & \text { a } & .164 & .034 & .286 & 4.860 & .000 & .082\end{array}$

Analysis 2 - Identity Moratorium

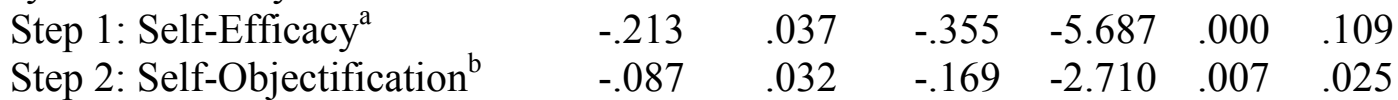

Analysis 3 - Identity Foreclosure

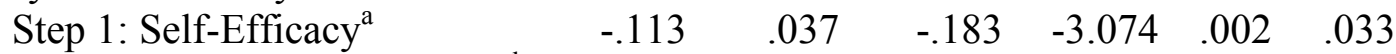

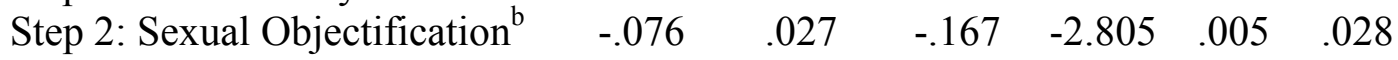

Analysis 4 - Identity Diffusion

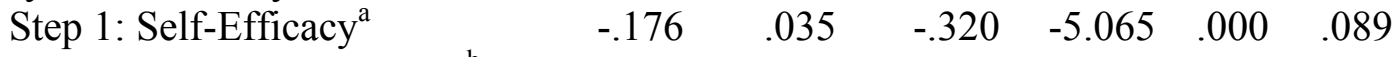

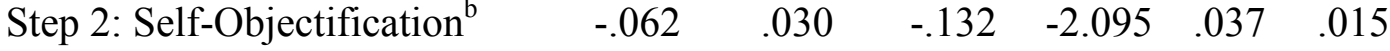

Analysis $1:{ }^{\mathrm{a}} \mathrm{R}^{2}=.08, p<.00$.

Analysis $2:{ }^{\mathrm{a}} \mathrm{R}^{2}=.08, p<.00 ;{ }^{\mathrm{b} \Delta} \mathrm{R}^{2}=.03, p<.05$.

Analysis $3:{ }^{\mathrm{a}} \mathrm{R}^{2}=.04, p<.05 ;{ }^{\mathrm{b} \Delta} \mathrm{R}^{2}=.03, p<.05$.

Analysis $4:{ }^{\mathrm{a}} \mathrm{R}^{2}=.07, p<.00 ;{ }^{\mathrm{b} \Delta} \mathrm{R}^{2}=.02, p<.05$. 


\section{Analysis 1 - Identity Achievement}

As indicated in Table 3, after self-efficacy was loaded into the equation, no other variable resulted in significance. This was predicted in hypothesis 2 .

\section{Analysis 2 - Identity Moratorium}

As indicated in Table 3: In the first step, self-efficacy was entered as it is the predictor variable with the highest regression coefficient $(B=-.213)$; while selfobjectification entered at the second step $(B=-.087)$. In this model, self-efficacy showed a unique contribution of .109 to the prediction of moratorium; while self-objectification contributed .025. Sexual objectification was not predictive of moratorium in this model.

\section{Analysis 3 - Identity Foreclosure}

As shown in Table 3, self-efficacy was entered first in Analysis 3 with $B=-.113$ and sexual objectification loaded second with $B=.076$. The unique contributions of the shared variance $\left(\mathrm{R}^{2}=.064\right)$ for self-efficacy and sexual objectification were $\mathrm{sr}^{2}=.033$ and .028 , respectively. Each variable contributed almost equally to the shared variance. Self-objectification was not predictive of foreclosure in this model.

\section{Analysis 4 - Identity Diffusion}

Like analysis 2, analysis 4 resulted in a predictive model for self-efficacy and self-objectification. As in the previous three models, self-efficacy was entered first into the hierarchical regression analysis $(B=-.176)$ and self-objectification entered second $(B=-.062)$ in the stepwise model. For this model, the $\mathrm{sr}^{2}$ indicated that self-efficacy

contributed the majority to the total $\mathrm{R}^{2}$ value while self-objectification contributed only a small proportion. Sexual objectification was not predictive of diffusion in this model. 


\section{CHAPTER 5}

\section{DISCUSSION}

The present study had two major objectives. The first objective was to discover if a relationship existed between sexual objectification and self-objectification (hypothesis 1). The second objective was to explore the predictive role of self-efficacy, selfobjectification, and sexual objectification to each of the identity statuses (hypothesis 2 and 3).

The data reported here demonstrated that, for young women, there is a positive correlation between sexual objectification and self-objectification, supporting hypothesis 1. This is an important finding as this correlation is the basis for objectification theory. Past research examining self-objectification presumed a correlation between sexual and self objectification, but only one study was found that actually examined it (Hill, 2002). The present study supports the findings of that previous study. Therefore, this finding supports previous research based on Fredrickson and Robert's (1997) Objectification Theory. It supports the idea that societal and cultural gender discourses impacts selfdefinition and self-construction. Socialization patterns, such as sexual objectification, can indeed become internalized by the individual and play a role in the expression of selfdefinition, values, and behaviors.

The present study also supported hypothesis 2 . Self-efficacy was predictive of each of the four identity statuses. Because self-efficacy was so highly correlated to each status (Table 2), it was entered first in each of the four hierarchical regressions (stepwise analyses were also performed for each of the statuses and self-efficacy always loaded 
first). As predicted, self-efficacy was significantly positively correlated with identity achievement and significantly and negatively correlated with identity foreclosure and diffusion. However, it was hypothesized that a positive correlation would be found between efficacy and moratorium, when in fact a strong negative correlation was found. According to Bandura (1997), it is only when people feel they have the power to produce results that they will attempt to make things happen. Identity moratorium is in a sense, trying to make identity happen. It is characterized by active participation in a self-search. Therefore, a negative correlation between moratorium and efficacy was unexpected. An explanation for this may be that moratorium, characterized as a state of upheaval and crisis and exploration, can also be characterized by erratic levels of efficacy. Identity researchers tell us that moratorium is an unsteady state (Erikson, 1968; Kroger, 1989; Marcia et al., 1993). Perhaps this unsteady and uncertain state temporarily reduces one's level of self-efficacy.

The present study lends partial support to hypothesis 3 , self and sexual objectification would add to the predictive models after self-efficacy for identity moratorium, foreclosure and diffusion. Self-objectification added to the predictive model for identity moratorium and diffusion. For identity moratorium, self-objectification contributed $18 \%$ to $\mathrm{R}^{2}$; while it contributed $14 \%$ to $\mathrm{R}^{2}$ for identity diffusion. This may be reflective of the lower self-efficacy levels related to moratorium and diffusion. Selfobjectification, as measured in this study, is based on ranking one's feelings of competency and appearance. If feelings of appearance are ranked higher than feelings of competency, one is self-objectifying. It stands to reason that these two identity statuses, 
which are negatively correlated with self-efficacy, would also result in a predictive model for self-objectification.

Sexual objectification added to the predictive model for identity foreclosure and accounts for almost half of the $\mathrm{R}^{2}$. However, the relationship between sexual objectification and identity foreclosure was an inverse relationship, which was not predicted. Because identity foreclosure is a conferred identity prescribed by others, including the culture at large, it was predicted that there would be a positive relationship between sexual objectification and identity foreclosure. One explanation for the converse findings could be that significant others play a stronger role than societal norms in a foreclosed status. In other words, familial behaviors and attitudes may act as a buffer against sexual, and therefore self, objectification (self-objectification did not result in a predictive model for identity foreclosure). This is a surprising find as identity foreclosure is considered a more negative identity outcome as the individual did not go through the exploration process of finding and defining oneself. Perhaps there is a positive aspect of adopting familial norms without exploring societal values and attitudes.

Finally, the present study confirms that objectification, both sexual and self, can affect female identity development in all statuses, including the optimal status of achievement. Sexualization of the female body has become such a gender norm that a full $68 \%$ of the females in this study who had achieved optimal identity development felt sexually objectified, and the three remaining statuses reported levels of $50 \%$ or higher. Results were similar for self-objectification, ranging from $42 \%$ to $62 \%$. In other words, in each of the four identity statuses, approximately half of the women in this study were self-objectifying. This finding is meaningful as objectification is not only affecting those 
women who are developing identity in a negative manner, but objectification is affecting women who are identity "healthy."

\section{Limitations}

There were several limitations with the present study. One major limitation was the use of the Self-Objectification Scale. Because it measures both competence and appearance but comes up with one total figure combining both subscales, it does not reflect those who may feel both competent and objectified. Another limitation of the present study was the use of ideological subscale of the EOM-EIS. Since interpersonal relationships may be more salient for female identity development (Gilligan, 1982), different findings may have emerged if the interpersonal subscales of the EOM-EIS had been used. Another limitation concerning the use of the EOM-EIS was the reliability of the identity diffusion scale, which was low $(\alpha=.57)$. Hence, findings relative to identity diffusion are somewhat questionable.

\section{Directions for Research}

Several recommendations have been deduced by the present study. Firstly, research needs to be conducted examining the relationship between self-efficacy and identity development, particularly identity moratorium, in which a negative relation emerged between these two variables. More information is needed on this status which is characterized by active exploration and a willingness to be open to new situations (Kroger, 2000) as these two characteristics appear to show some commonality to selfefficacy. Because a negative correlation was found, something additional may be occurring during the moratorium process or perhaps the lack of commitment associated with moratoria may be counteractive to efficacy. 
Next, research in identity development, with a crucial look at objectification, should continue. The current study suggests that objectification plays some role in identity formation, specifically moratorium, foreclosure and diffusion. Particular attention should focus on identity foreclosure, as its negative relationship to sexual objectification may indicate protective qualities of foreclosure and, therefore, may lend support to view this status in a more positive light.

Future research should also be conducted examining gender discourses such as sexualization practices. Socialization patterns that contribute to gender norms, particularly those that result in gender status discrepancy, need to be well researched and explained so that they may be eradicated. The fact that $63 \%$ of women in this study felt sexually objectified says something rather perverse about the society in which they live. However, studies also need to examine these factors in males. They, too, are increasingly being subjected to unattainable cultural ideals and report feelings of dissatisfaction (Lorenzen, Grieve, \& Thomas, 2004).

Finally, the relationship between self-objectification and self-efficacy would benefit from more careful examination. The current view of self-objectification, a deficiency in competency with a focus on appearance, may be limited in scope. Individuals may be high in efficacy, competency, and self-objectification. New tools need to be developed to accurately measure and account for discrepancies.

In summary, the present study contributes to the knowledge base of selfdevelopment. It can be concluded from this study that sexually objectifying messages are related to domains of self-development in young females; notable in this study is selfobjectification. This finding opens up a myriad of questions, such as what other areas of 
self-development is sexual objectification related to and what are the possible consequences? Because the study of self-development is convoluted at best, the present study offers only a small detangling of the issue. However, its importance should not be minimized because of the pervasive nature of sexual objectification and its potential to affect young females.

This study also contributes to the area of identity development. It was found that sexual objectification and self-objectification do play some role in female identity development, particularly that of identity moratorium, foreclosure and diffusion. While self-objectification played only a minor yet significant role in identity moratorium and diffusion, sexual objectification was quite significant in identity foreclosure. Surprisingly, it is the inverse nature of the relationship that makes this finding so intriguing. The study offers reasoning for identity researchers to examine the possible protective effects of a foreclosed status. Thus far, research indicates that a foreclosed status is less than healthy or less than optimal. The present study suggests something positive about foreclosure. 


\section{REFERENCES}

Adams, G.R., Bennion, L., \& Huh, K. (1989). Objective measure of ego identity status: A reference manual. Available from Gerald Adams, Department of Family Studies, University of Guelph, Guelph, Ontario.

Bandura, A. (1997). Self-efficacy: The exercise of control. New York: W.H. Freeman and Company.

Bartky, S.L. (1990). Femininity and domination: Studies in the phenomenology of oppression. New York: Routledge.

Calogero, R.M. (2004). A test of objectification theory: The effect of the male gaze on appearance concerns in college women. Psychology of Women Quarterly, 28, 1621.

Calogero, R.M., Davis, W.N, \& Thompson, J.K. (2005). The role of self-objectification in the experience of women with eating disorders. Sex Roles, 52, 43-50.

Chibucos, T.R. \& Leite, R.W. (2005). Readings in family theory. Thousand Oaks: Sage.

Csikszentmihalyi, M. (1990). Flow: The psychology of optimal experience. New York: Harper \& Row.

Cusumano, D.L. \& Thompson, J.K. (1997). Body image and body shape ideals in magazines: Exposure, awareness and internalization. Sex Roles, 37, 701-721.

Daubenmeir, J.J. (2005). The relationship of yoga, body awareness, and body responsiveness to self-objectification and disordered eating. Psychology of Women Quarterly, 29, 207-219.

Erikson, E. (1950). Childhood and society. New York: Norton \& Co.

Erikson, E. (1956). The problem of ego identity. Journal of American Psychoanalytic 
Association, 4, 56-121.

Erikson, E. (1963). Childhood and society (Rev. ed.). New York: Norton \& Co.

Erikson, E. (1968). Identity: Youth and crisis. New York: Norton \& Co.

Festinger, (1957). A theory of cognitive dissonance. Stanford: Stanford University Press.

Fredrickson, B.L. \& Harrison, K. (2005). Throwing like a girl: Self-objectification predicts adolescent girls' motor performance. Journal of Sport and Social Issues, 29, 79-101.

Fredrickson, B.L. \& Roberts, T. (1997). Objectification theory: Toward understanding women's lived experiences and mental health risks. Psychology of Women Quarterly, 21, 173-296.

Fredrickson, B.L., Roberts, T., Noll, S.M., Quinn, D.M., \& Twenge, J.M. (1998). That swimsuit becomes you: Sex differences in self-objectification, restrained eating, and math performance. Journal of Personality and Social Psychology, 75, 269284.

Gapinski, K.D., Brownell, K.D., \& LaFrance, M. (2003). Body objectification and "fat talk": Effects on emotion, motivation and cognitive performance. Sex Roles, 48, 377-388.

Gilligan, C. (1982). In a different voice. Cambridge, MA: Harvard University Press.

Gordon, L. (1979). The struggle for reproductive freedom: Three stages of feminism. In Z. Eisenstein (Ed.), Capitalist patriarchy and the case for socialist feminism (pp. 107-136). New York: Monthly Review Press.

Grauerholz, E. \& King, A. (1997). Prime time sexual harassment. Violence Against Women, 3, 129-149. 
Greenleaf, C. (2005). Self-objectification among physically active women. Sex Roles, 52, $51-62$.

Groesz, L.M., Levine, M.P., \& Murnen, S.K. (2002). The effect of experimental presentation of thin media images on body satisfaction: a meta-analytic review. International Journal of Eating Disorders, 31, 1-16.

Harter, S. (1999). The construction of the self: A developmental perspective. New York: Guilford Press.

Hill, M. (2002). Examining objectification theory: Sexual objectification's link with selfobjectification and moderation by sexual orientation and age in white women (Doctoral dissertation, University of Akron, 2002). Dissertation Abstracts International, 63, 3515.

James, W. (1890). Principles of psychology. New York: Holt.

Johnston, J. E. (1997). Appearance obsession: Women's reactions to men's objectification of their bodies. In R. Levant \& G. Brooks (Eds.) Men and sex: New psychological perspectives (pp. 61-83). Hoboken: Wiley \& Sons, Inc.

Kroger, J. (1989). Identity in adolescence: The balance between self and other. New York: Routledge

Kroger, J. (2000). Identity Development: Adolescence through adulthood. Thousand Oaks: Sage Publications, Inc.

Lin, C.A. (1998). Uses of sex appeals in prime-time television commercials. Sex Roles, $38,461-475$.

Lorenzen, L.A., Grieve, F.G., \& Thomas, A. (2004). Exposure to muscular male models decreases men's body satisfaction. Sex Roles, 51, 723-748. 
Luszczynska, A., Gutiérrez-Doña, B. \& Schwarzer, R. (2005). General self-efficacy in various domains of human functioning: Evidence from five countries. International Journal of Psychology, 40, 80-89.

Marica, J.E. (1966). Development and validation of ego identity status. Journal of Personality and Social Psychology. 5, 551-558.

Marcia, J.E. (1980). Identity in adolescence. In J. Adelson (Ed.), Handbook of adolescent psychology (pp. 159-187). New York: Wiley.

Marcia, J.E. (1994). Identity and psychotherapy. In S.L. Archer (Ed.), Interventions from adolescent identity development (pp. 29-46). Thousand Oaks: Sage.

Marcia, J.E., Waterman, A.S., Matteson, D.R., Archer, S.L., \& Orlofsky, J.L. (1993). Ego identity: A handbook for psychological research. New York: Springer-Verlag.

Masters, W.H. \& Johnson, V.E. (1970). Human sexual inadequacy. Boston: Little, Brown, \& Co.

McKinley, N.M. (1998). Gender differences in undergraduates' body esteem: The mediating effect of objectified body consciousness and actual/ideal weight discrepancy. Sex Roles, 19, 113-123.

Merskin, D. (2004). Reviving Lolita? A media literacy examination of sexual portrayals of girls in fashion advertising. American Behavioral Scientist, 48, 119-129.

Moradi, B., Dirks, D. \& Matteson, A.V. (2005). Roles of sexual objectification experiences and internalization of standards of beauty in eating disorder symptomatology : A test and extension of objectification theory. Journal of Counseling Psychology, 52, 420-428.

Muehlenkamp, J.J., \& Saris-Baglama, R.N. (2002). Self-objectification and its 
psychological outcomes for college women. Psychology of Women Quarterly, 26, 371-379.

Mulvey, L. (1975). Visual pleasure in narrative cinema. Screen (16), 6-16.

Noll, S.M. \& Fredrickson, B.L. (1998). A mediational model linking self-objectification, body shame, and disordered eating. Psychology of Women Quarterly, 22, 623636.

Paranjpe, A.C. (1975). In search of identity. New York: John Wiley \& Sons.

Perosa, L.M., Perosa, S.L., \& Tam, H.P. (2002). Intergenerational systems theory and identity development in young adult women. Journal of Adolescent Research, 17, 235-259.

Rosenberg, M. (1979). Conceiving the self. New York: Basic Books, Inc.

Schwarzer, R. \& Jerusalem, M. (1995). Generalized self-efficacy scale. In J. Weinman, S. Wright \& M. Johnston (Eds.), Measures in health psychology: A users portfolio (pp. 35-37). Windsor: Nelson.

Sherer, M., Maddux, J.E., Mercandante, B., Prentice-Dunn, S., Jacobs, B., \& Rogers, R.W. (1981). The self-efficacy scale: Construction and validation. Psychological Reports, 51, 663-671.

Shweder, R.A., Goodnow, J., Hatano, G., LeVine, R.A., Markus, H. \& Miller, P. (1998). The cultural psychology of development: One mind, many mentalities. In W. Damon and R. Lerner's (Eds.) Handbook of Child Psychology, 5th Ed. (pp. 865937) New York: John Wiley \& Sons, Inc.

Slater, A. \& Tiggemann, M. (2002). A test of self-objectification theory in adolescent girls. Sex Roles, 46, 343-388. 
Tabachnick, B.G. \& Fidell, L.S. (1996). Using multivariate statistics ( $3^{\text {rd }}$ Ed.). Harper Collins.

Tiggemann, M., \& Kuring, J.K. (2004). The role of body objectification in disordered eating and depressed mood. British Journal of Clinical Psychology, 43, 299-311.

Tiggemann, M. \& Slater, A. (2004). Thin ideals in music television: A source of social comparison and body dissatisfaction. International Journal of Eating Disorders, $35,48-58$.

Tong, Y. \& Song, S. (2004). A study of general self-efficacy and subjective well-being of low ses college students in a Chinese university. College Student Journal, 38, $637-643$

Wiederman, M. (2000). Women's body image self-consciousness during physical intimacy with a partner. Journal of Sex Research, 37, 60-68.

Young, I.M. (1990). Throwing like a girl and other essays in feminist philosophy and social theory. Bloomington: Indiana University Press. 
APPENDICES 
APPENDIX A

CONSENT FORM 


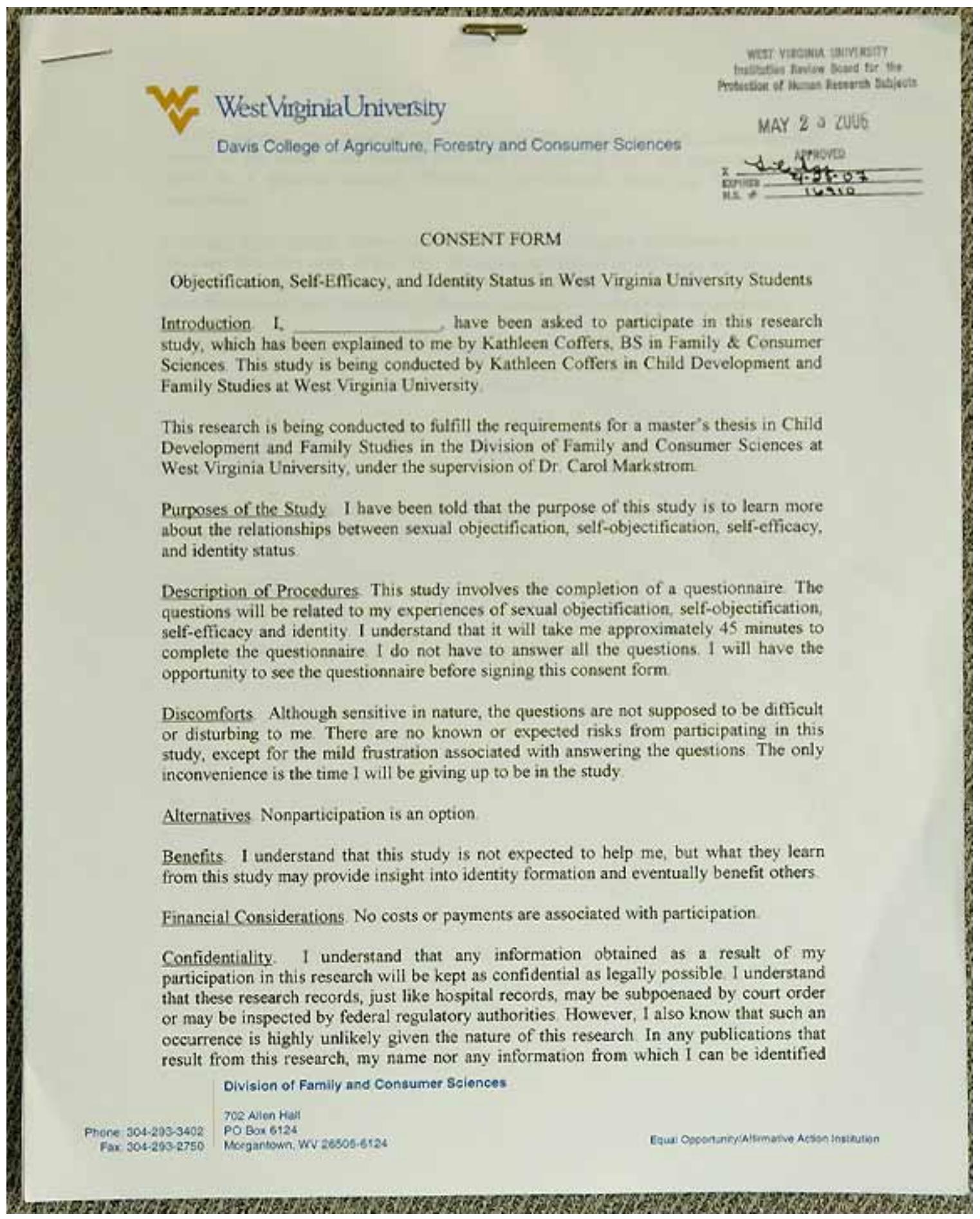




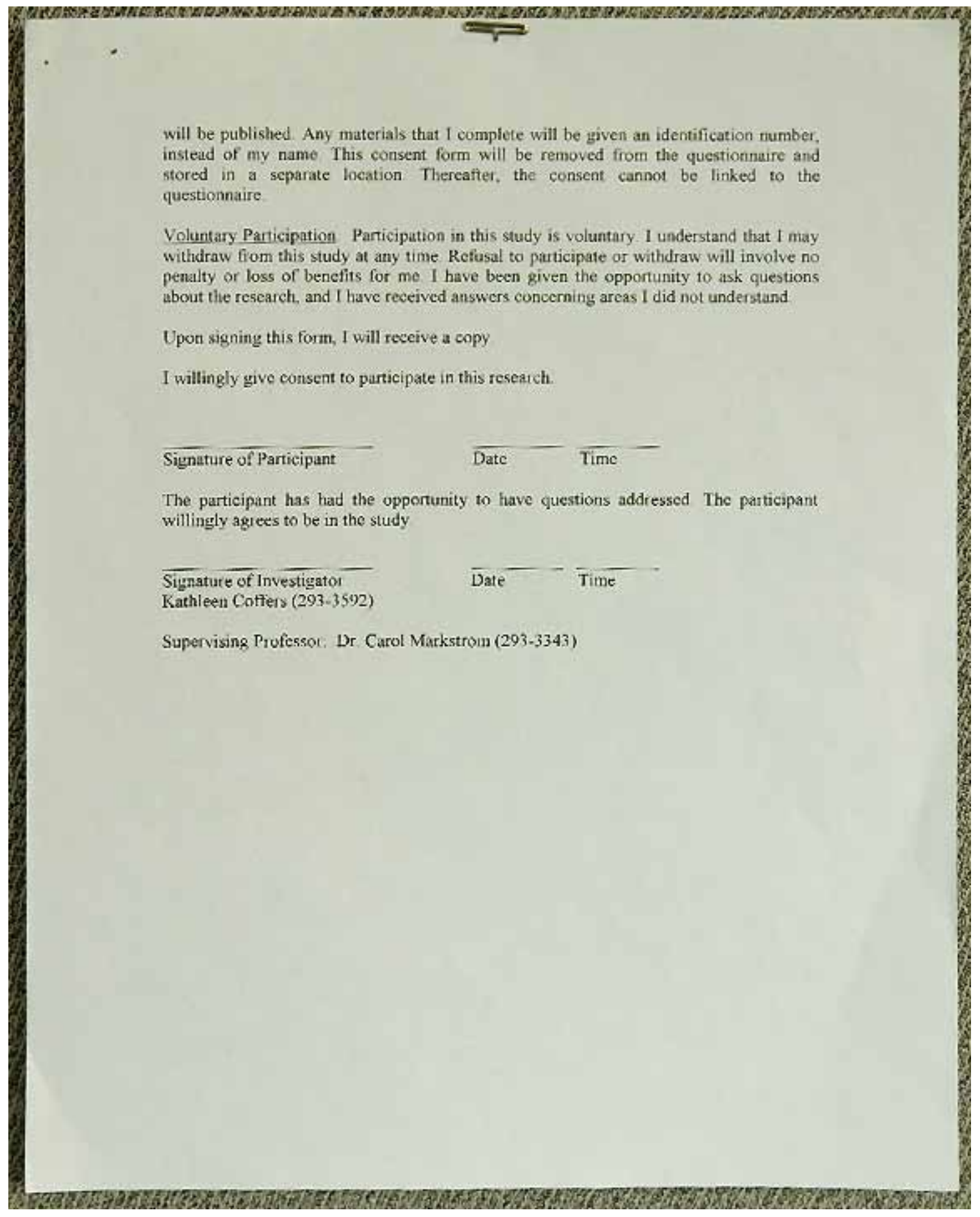


APPENDIX B

BACKGROUND QUESTIONNAIRE 


\section{Part A}

TO BE COMPLETED BY FEMALES AND MALES.

This page is designed to provide us with general information which will help us describe who participated in this study. This information will be confidential.

\section{Background Questionnaire}

1. Age:

2. Height:

3. Weight:

Questions 4-9, circle one response for each question. For parent education item, circle one response for each parent.

4. Sex: M F

5. Class Status: Freshman Sophomore Junior Senior

6. Relationship status: casually dating seriously dating committed partnership or marriage

7. Ethnicity: African American American Indian Asian American Latino White Other

8. Sexual Orientation: Heterosexual Homosexual Bisexual

9. Parent Education:

Mother

Father

did not complete high school

completed high school

attended college

obtained bachelors degree

obtained masters degree

obtained doctorate did not complete high school

completed high school

attended college

obtained bachelors degree

obtained masters degree

obtained doctorate 
APPENDIX C

SEXUAL OBJECTIFICATION QUESTIONNAIRE - WOMEN 


\section{Part B - Experience Survey}

\section{TO BE COMPLETED BY FEMALES ONLY. MALES GO TO PART C.}

Instructions: Please think carefully about your lifetime as you answer the following questions. Please use pencil or pen to color in the appropriate response. Use the following guidelines in answering:

\begin{tabular}{|c|c|c|c|c|c|}
\hline 1 & 2 & 3 & 4 & 5 & 6 \\
\hline NEVER & $\begin{array}{c}\text { ONCE IN A } \\
\text { WHILE }\end{array}$ & SOMETIMES & A LOT & $\begin{array}{c}\text { MOST OF } \\
\text { THE TIME }\end{array}$ & $\begin{array}{c}\text { ALMOST ALL } \\
\text { OF THE TIME }\end{array}$ \\
\hline
\end{tabular}

1. How many times have you been "checked out" (i.e., had your body stared at in an intrusive way) by a person in public?

(1) (2) (3) (4) (5) (6)

2. How many times has your romantic partner (current or past) ever "checked out" other women in your presence?

(1) (2) (3) (4) (5) (6)

3. How many times have you had someone stare at your breasts while talking to you?

(1) (2) (3) (4) (5) (6)

4. How many times have you experienced cat calls or whistles about your looks?

(1) (2) (3) (4) (5) (6)

5. How many times have you been in a situation where someone made sexual comments about your body specifically (positively or negatively)?

(1) (2) (3) (4) (5) (6)

6. How many times have you been in a situation where someone made sexual comments about another woman's body or women's bodies in general (either positively or negatively)?

(1) (2) (3) (4) (5) (6)

7. How many times have you been in a situation where someone made evaluative or judging comments on your weight or body shape? .

(1) (2) (3) (4) (5) (6)

8. How many times have you been in a situation where someone made evaluative or judging comments on another woman's weight/body shape or women's weight/body shape in general?

(1) (2) (3) (4) (5) (6)

9. How many times have you felt that a date was more interested in your body (and gaining access to it) than in you as a person?

(1) (2) (3) (4) (5) (6)

10. How many times have you looked at women's fashion magazines such as Glamour, Cosmopolitan, Vogue, or similar magazines? ....

11. How many times have you looked at women's sexually suggestive swimsuit or lingerie catalogs such as Victoria's Secret?

(1) (2) (3) (4) (5) (6)

12. How many times have you looked at, or been exposed to, pornographic material displaying women's bodies?

(1) (2) (3) (4) (5) (6)

13. How many times have you seen advertisements where a woman's body is used to sell things such as cars, drinks, etc.?

(1) (2) (3) (4) (5) (6)

14. How many times has someone stared at or leered at you in a way that made you feel uncomfortable?

(1) (2) (3) (4) (5) (6) 
15. How many times has someone made offensive, sexualized gestures toward you (e.g., pelvic thrusts, stroking, pantomime of masturbation or intercourse)?

(1) (2) (3) (4) (5) (6)

16. How many times have you been in a situation where someone told suggestive (sexual) stories or offensive jokes about women?

(1) (2) (3) (4) (5) (6)

17. How many times have you been in a situation where someone made crude sexual remarks about your body specifically which made you uncomfortable?

(1) (2) (3) (4) (5) (6)

18. How many times have you been in a situation where someone made crude sexual remarks about another woman's body or women's bodies in general which made you uncomfortable?

(1) (2) (3) (4) (5) (6)

19. How many times have you been in a situation where someone gave you unwanted sexual attention?

(1) (2) (3) (4) (5) (6)

20. How many times have you been in a situation where someone touched you in a way that made you feel uncomfortable?

(1) (2) (3) (4) (5) (6)

21. How many times have you received sexually obscene phone calls or had a sexually obscene message left on your answering machine or email?

(1) (2) (3) (4) (5) (6)

22. How many times has someone spread false rumors about your sex life with them or others?

(1) (2) (3) (4) (5) (6)

23. How many times has someone asked you questions about your sex or romantic life that were clearly none of their business - such as someone you just met or a professor/boss/coworker?

(1) (2) (3) (4) (5) (6)

24. How many times has someone made general sexist remarks in front of you, such as put-downs about women's abilities, intelligence or roles in society?

(1) (2) (3) (4) (5) (6) 


\section{APPENDIX D}

\section{SELF-OBJECTIFICATION QUESTIONNAIRE}




\section{Part D - Body Attributes}

\section{TO BE COMPLETED BY FEMALES AND MALES.}

Instructions: We are interested in how people think about their bodies. The questions below identify 10 different attributes. We would like you to rank order these body attributes from that which has the greatest impact on your physical self-concept, to that which has the least impact on your physical self-concept. NOTE: It does not matter how you describe yourself in terms of each attribute. For example, fitness level can have a great impact on your physical self-concept regardless of whether you consider yourself to be physically fit, not physically fit, or any level in between. Please first read over all the attributes. Then, record your rank by writing the letter of the attribute.

\section{WHEN CONSIDERING YOUR PHYSICAL SELF-CONCEPT, HOW IMPORTANT IS...}
a. physical coordination?
f. physical attractiveness?
b. health?
g. energy level?
c. weight?
h. firm/sculpted muscles?
d. strength?
i. physical fitness level?
e. sex appeal?
j. measurements (e.g. waist, chest)?

\section{LETTER OF ATTRIBUTE}

MOST IMPORATANT ...

SECOND MOST IMPORTANT

THIRD MOST IMPORTANT

FOURTH MOST IMPORTANT

FIFTH MOST IMPORTANT

SIXTH MOST IMPORTANT

SEVENTH MOST IMPORTANT

EIGTH MOST IMPORTANT

NINTH MOST IMPORTANT.

LEAST IMPORTANT 
APPENDIX E

GENERAL SELF-EFFICACY SCALE 
Part E - Self-Perception Survey

TO BE COMPLETED BY FEMALES AND MALES.

Instructions: Please color in the response that best describes you. Use the guidelines in answering:

\begin{tabular}{|c|c|c|c|c|c|}
\hline 1 & 2 & 3 & 4 & 5 & 6 \\
\hline $\begin{array}{c}\text { STRONGLY } \\
\text { DISAGREE }\end{array}$ & DISAGREE & $\begin{array}{c}\text { SOMEWHAT } \\
\text { DISAGREE }\end{array}$ & $\begin{array}{c}\text { SOMEWHAT } \\
\text { AGREE }\end{array}$ & AGREE & $\begin{array}{c}\text { STRONGLY } \\
\text { AGREE }\end{array}$ \\
\hline
\end{tabular}

1. When I make plans, I am certain I can make them work.

(1) (2) (3) (4) (5) (6)

2. One of my problems is that I cannot get down to work when I should.

3. If I can't do a job the first time, I keep trying until I can. (1) (2) (3) (4) (5) (6)

4. When I set important goals for myself, I rarely achieve them. (1) (2) (3) (4) (5) (6)

5. I give up on things before completing them. (1) (2) (3) (4) (5) (6)

6. I avoid facing difficulties.

7. If something looks too complicated, I will not even bother to try. (1) (2) (3) (4) (5) (6)

8. When I have something unpleasant to do, I stick to it until I finish. (1) (2) (3) (4) (5) (6)

9. When I decide to do something, I go right to work on it. (1) (2) (3) (4) (5) (6)

10. When trying to learn something new, I soon give up if I am not initially successful.

11. When unexpected problems occur, I don't handle them well. (1) (2) (3) (4) (5) (6)

12. I avoid trying to learn new things when they look difficult to me. (1) (2) (3) (4) (5) (6)

13. Failure just makes me try harder. (1) (2) (3) (4) (5) (6)

14. I feel insecure about my ability to do things. (1) (2) (3) (4) (5) (6)

15. I am a self-reliant person. (1) (2) (3) (4) (5) (6)

16. I give up easy.

17. I do not seem capable of dealing with most problems that come up in life. 
APPENDIX F

IDENTITY QUESTIONNAIRE 


\section{Part F}

\section{TO BE COMPLETED BY FEMALES AND MALES.}

Instructions: Please color in the response that best describes you. Use the following guidelines in answering:

\begin{tabular}{|c|c|c|c|c|c|}
\hline 1 & 2 & 3 & 4 & 5 & 6 \\
\hline $\begin{array}{c}\text { STRONGLY } \\
\text { DISAGREE }\end{array}$ & DISAGREE & SOMEWHAT & SOMEWHAT & AGREE & STRONGLY \\
& & DISAGREE & AGREE & & AGREE \\
\hline
\end{tabular}

1. I haven't chosen the occupation I really want to get into, and I'm just working at what is available until something better comes along.

2. When it comes to religion I just haven't found anything that appeals and I don't really feel the need to look.

3. There's no single "life style" which appeals to me more than another.

4. Politics is something that I can never be to sure about because things change so fast. But I do think it's important to know what I can politically stand for and believe in.

5. I'm still trying to decide how capable I am as a person and what work will be right for me.

(1) (2) (3) (4) (5) (6)

6. I don't give religion much thought and it doesn't bother me one way or the other.

(1) (2) (3) (4) (5) (6)

7. I'm looking for an acceptable perspective for my own "life style", but haven't really found it yet.

(1) (2) (3) (4) (5) (6)

8. I haven't really considered politics. It just doesn't excite me much.

(1) (2) (3) (4) (5) (6)

9. I might have thought about a lot of different jobs, but there's never really been any question since my parents said what they wanted.

(1) (2) (3) (4) (5) (6)

10. A person's faith is unique to each individual. I've considered and reconsidered it myself and know what I can believe.

(1) (2) (3) (4) (5) (6)

11. After considerable thought I've developed my own individual viewpoint of what is for me an ideal "life style" and don't believe anyone will be likely to change my perspective.

(1) (2) (3) (4) (5) (6)

12. I guess I'm pretty much like my folks when it comes to politics. I follow what they do in terms of voting and such.

(1) (2) (3) (4) (5) (6)

13. I'm not really interested in finding the right job, any job will do. I just seem to flow with what is available.

(1) (2) (3) (4) (5) (6)

14. I'm not sure what religion means to me. I'd like to make up my mind but I'm not done looking yet.

(1) (2) (3) (4) (5) (6)

15. My own views on a desirable life style were taught to me by my parents and I don't see any need to question what they taught me...

(1) (2) (3) (4) (5) (6) 
16. There are so many different political parties and ideals. I can't decide which to follow until I figure it all out.

(1) (2) (3) (4) (5) (6)

17. It took me a while to figure it out, but now I really know what I want for a career.

(1) (2) (3) (4) (5) (6)

18. Religion is confusing to me right now. I keep changing my views on what is right and wrong for me.

(1) (2) (3) (4) (5) (6)

19. In finding an acceptable viewpoint to life itself, I find myself engaging in a lot of discussions with others and some self exploration.

(1) (2) (3) (4) (5) (6)

20. I've thought my political beliefs through and realize I can agree with some and not other aspects of what my parents believe.

(1) (2) (3) (4) (5) (6)

21. My parents decided a long time ago what I should go into for employment and I'm following through their plans.

(1) (2) (3) (4) (5) (6)

22. I've gone through a period of serious questions about faith and can now say I understand what I believe in as an individual.

(1) (2) (3) (4) (5) (6)

23. My parents' views on life are good enough for me, I don't need anything else.

(1) (2) (3) (4) (5) (6)

24. I'm not sure about my political beliefs, but I'm trying to figure out what I can truly believe in.

(1) (2) (3) (4) (5) (6)

25. It took me a long time to decide but now I know for sure what direction to move in for a career.

(1) (2) (3) (4) (5) (6)

26. I attend the same church as my family has always attended. I've never really questioned why.

(1) (2) (3) (4) (5) (6)

27. I guess I just kind of enjoy life in general, and I don't see myself living by any particular viewpoint to life.

(1) (2) (3) (4) (5) (6)

28. I really have never been involved in politics enough to have made a firm stand one way or the other.

(1) (2) (3) (4) (5) (6)

29. I just can't decide what to do for an occupation. There are so many possibilities.

(1) (2) (3) (4) (5) (6)

30. I've never really questioned my religion. If it's right for my parents it must be right for me.

(1) (2) (3) (4) (5) (6)

31. After a lot of self-examination I have established a very definite view on what my own life style will be

(1) (2) (3) (4) (5) (6)

32. My folks have always had their own political and moral beliefs about issues like abortion and mercy killing and I've always gone along accepting what they have.

(1) (2) (3) (4) (5) (6) 


\section{$\underline{\text { Personal Data }}$}

Name:

Kathleen Reilly Coffers

Date of Birth:

September 28, 1966

Place of Birth:

Long Island, New York

\section{$\underline{\text { Education }}$}

2006 West Virginia University, Morgantown, WV

M.S. Family and Consumer Sciences Major: Child Development and Family Studies

2004 West Virginia University, Morgantown, WV

B.S. Family and Consumer Sciences Major: Child Development and Family Studies

\section{Experience}

01/06 - Present West Virginia University: Division of Family and Consumer Sciences

Visiting Lecturer - Public Communications

08/05 - 07/06 Graduate Research Assistant in Child Development

08/04-07/05 Graduate Research Assistant in Textiles and Merchandising

\section{$\underline{\text { Academic Honors }}$}

Gamma Sigma Delta Award of Merit

Gamma Sigma Delta Scholarship

Presidential Award for Excellence in Scholarship

Davis College Award for Outstanding Scholarship and Leadership

West Virginia Community Educational Outreach Scholarship 